
\title{
3 Research Square \\ Modeling and Estimation of Cutting Forces in Ball Helical Milling Process
}

\section{Haiyan Wang ( $\nabla$ hywang16@126.com )}

Northeastern University at Qinhuangdao

\section{Kexin Tao}

School of Control Engineering, Northeastern University at Qinhuangdao, Qinhuangdao, Hebei Province, CHINA

\section{Tian Jin}

School of Control Engineering, Northeastern University at Qinhuangdao, Qinhuangdao, Hebei Province, CHINA

\section{Research Article}

Keywords: Ball helical milling, Cutting forces, Cutting coefficients, Instantaneous force method

Posted Date: March 1st, 2021

DOl: https://doi.org/10.21203/rs.3.rs-258262/v1

License: (1) (1) This work is licensed under a Creative Commons Attribution 4.0 International License. Read Full License

Version of Record: A version of this preprint was published at The International Journal of Advanced Manufacturing Technology on August 18th, 2021. See the published version at https://doi.org/10.1007/s00170-021-07817-6. 


\title{
Modeling and estimation of cutting forces in ball helical milling process
}

\author{
Haiyan Wang*. Kexin Tao · Tian Jin
}

School of Control Engineering, Northeastern University at Qinhuangdao, Qinhuangdao, 066004, Hebei, CHINA

\author{
$\bowtie$ Wang Haiyan, School of Control Engineering, Northeastern University at Qinhuangdao, Qinhuangdao, Hebei \\ Province, CHINA, 066004 \\ E-mail: hywang16@126.com
}

\begin{abstract}
Milling forces play an important role in the milling process and are generally calculated by the mechanistic or numerical methods, reliable model of cutting force is very important for the simulation of milling process, which has big scientific significance to further improve machining quality. Ball helical milling technology is used to make holes based on the cutting principle of helical milling using ball end cutter, due to the influence of spherical surface machining characteristic, the modeling of cutting force in ball helical milling is difficult. Therefore, the main purpose of this paper is to first establish an analytical cutting force model in the ball helical milling process. Considering cutting characteristics in the axial feed, the kinematics of ball helical milling is first presented, then the chip thickness distribution in different directions along the cutting edges are predicted. Furthermore, based on the characteristics of helical milling technology and geometry shape of ball end mill and the classical mechanical cutting force model, through the study on the ball-end milling mechanics, a new relatively accurate theoretical cutting force model is established. At the same time, cutting force coefficients are identified through instantaneous force method according to the Ti-alloy experimental research result. Finally, higher simulation precision of cutting force model in ball helical milling process is received.
\end{abstract}

Keywords Ball helical milling · Cutting forces · Cutting coefficients · Instantaneous force method

\section{Declarations}

Funding : Natural Science Foundation of Hebei Province, China (E2020501014)

Conflicts of interest/Competing interests: Not applicable

Availability of data and material:

The datasets used or analysed during the current study are available from the corresponding author on reasonable request.

Code availability: Not applicable

Author contributions: Not applicable 


\title{
Modeling and estimation of cutting forces in ball helical milling process
}

\begin{abstract}
Milling forces play an important role in the milling process and are generally calculated by the mechanistic or numerical methods, reliable model of cutting force is very important for the simulation of milling process, which has big scientific significance to further improve machining quality. Ball helical milling technology is used to make holes based on the cutting principle of helical milling using ball end cutter, due to the influence of spherical surface machining characteristic, the modeling of cutting force in ball helical milling is difficult. Therefore, the main purpose of this paper is to first establish an analytical cutting force model in the ball helical milling process. Considering cutting characteristics in the axial feed, the kinematics of ball helical milling is first presented, then the chip thickness distribution in different directions along the cutting edges are predicted. Furthermore, based on the characteristics of helical milling technology and geometry shape of ball end mill and the classical mechanical cutting force model, through the study on the ball-end milling mechanics, a new relatively accurate theoretical cutting force model is established. At the same time, cutting force coefficients are identified through instantaneous force method according to the Ti-alloy experimental research result. Finally, higher simulation precision of cutting force model in ball helical milling process is received.
\end{abstract}

Keywords Ball helical milling; Cutting forces; Cutting coefficients; Instantaneous force method

\section{Nomenclature}

$\begin{array}{ll}F(\mathrm{~N}) & \text { Cutting force } \\ i_{0}\left(^{\mathrm{o}}\right) & \text { Nominal helix angle } \\ i\left(^{\mathrm{o}}\right) & \text { Local helix angle } \\ N & \text { Number of cutting edges } \\ D_{\mathrm{t}}(\mathrm{mm}) & \text { Tool diameter } \\ D_{h}(\mathrm{~mm}) & \text { Hole-making diameter } \\ a_{p}(\mathrm{~mm} / \mathrm{r}) & \text { Depth of cut in axial direction } \\ \alpha\left(^{\mathrm{o}}\right) & \text { Ramp(helix) angle } \\ n(\mathrm{rpm}) & \text { Rotational speed } \\ n_{r}(\mathrm{rpm}) & \text { Orbital speed } \\ d(\mathrm{~mm}) & \text { Efficient diameter } \\ \theta_{j}\left({ }^{\mathrm{o}}\right) & \text { Rotational angle at any times } \\ \phi\left(^{\mathrm{o}}\right) & \text { Orbital angle } \\ s_{a}(\mathrm{~mm} / \mathrm{t}) & \text { Feed rate in the axial direction }\end{array}$

$t(\mathrm{~s})$

$S_{t}(\mathrm{~mm} / \mathrm{t})$

$R_{t}(\mathrm{~mm})$

$\mathrm{d} b(\mathrm{~mm})$

$\mathrm{d} S(\mathrm{~mm})$

$r(z)(\mathrm{mm})$

$\psi(z)\left(^{\mathrm{o}}\right)$

$F_{\text {r }}(\mathrm{N})$

$F_{x}(\mathrm{~N})$

$F_{y}(\mathrm{~N})$

$\alpha_{r}\left({ }^{\mathrm{o}}\right)$

$R\left(z_{i}\right)(\mathrm{mm})$

Movement time

Feed rate at tool center

Radius in the sphere surface

Cutting width

Length of the edge discrete element

Cutting efficient radius

Radial lag angle

$i\left(z_{i}\right)\left(^{\mathrm{o}}\right)$

Radial force

$\Delta y(\mathrm{~mm})$

$h(\mathrm{~mm})$

Cutting forces in the $x$ direction

$V_{s}(\mathrm{~m} / \mathrm{min})$

Cutting forces in the $y$ direction

$V(\mathrm{~m} / \mathrm{min})$

Constant radial rake angle

$K_{t c} 、 K_{r c}$ and

Local cutter radius

$K_{a c}\left(\mathrm{~N} / \mathrm{mm}^{2}\right)$

Cutting force coefficients in tangential, radial and axial direction $K_{t e} 、 K_{r e}$ and $K_{a e}(\mathrm{~N} / \mathrm{mm}) \quad$ Rubbing force coefficients in tangential, radial and axial direction 


\section{Introduction}

Helical milling has attracted much attention in typical hole-making technology for difficult-to-cut materials, such as titanium alloy and CFRP, during the machining process, the rotating cutter that traverses a helical trajectory to generate a hole of a diameter larger than that of the tool, it can adjust the eccentricity without changing tool to obtain different diameters of holes. As one of the new hole machining technique, helical milling offers many advantages compared to conventional drilling. For example, one tool can be used to produce different borehole geometries by changing the process parameters of helical milling, so it offers the possibility for a dynamic correction of the bore diameter during the hole-making process. Other advantages of helical milling are lower process forces, better chip transportation than conventional drilling .

Ball end cutter, as a kind of general tool, can be used to complete small axial feed, so it also can be used to complete helical milling process, but the dynamic milling process of ball end cutter is relative complex, which is not only related to the basic machining parameters and tool geometry, but also has a complex relationship with the dynamic change of cutting zone.

Cutting force is a very important parameter in the cutting process, appropriate prediction of the force components collaborates with the correct choice of the cutting parameters can avoid machine tool vibrations, improve workpiece surface quality and guarantee process stability. Through modeling and analysis of cutting force, the cutting state with tool wear and machining quality can be further understood and discussed. Wang et al.[1-2] first mainly considered the processing of periphery edge and frontal edges respectively in the helical milling of titanium alloy and carbon fiber composites, established a relatively accurate analytical model of cutting force, identified the cutting force coefficients through the average-based force method, and modified cutting force coefficients considering the effect of cutting parameters. Liu et al. [3] used a combination of simulation and experiment to study the cutting force modeling method for the helical milling process. Ventura et al. [4] described an approach for modeling the cutting forces in helical milling process based on the analysis of tool contact angle and respective depth of cut. The model could be used to predict the behavior and magnitude of the force acting on the tool. Zhou et al. [5] analyzed and described the undeformed chip geometries produced by each tooth and the instantaneous chip geometries, developed non-linear cutting force model. The results showed that the model could be used to predict the cutting force generated in the steady cutting stage. Shang et al. [6] developed a cutting force model and built a new calibration method of cutting force coefficients in helical milling process, but the results showed that average coefficients did not suit for helical milling process. Rey et al. [7]set up a cutting forces model depending on the tool geometry and cutting conditions in taking into account the parameters defining the trajectory and the tool geometry, the influence of the side edge and the bottom edge was considered in detail, the radial and axial effects of the three-way cutting forces were considered respectively, and the corresponding unique coefficient identification experiment was carried out by analyzing the basic cutting process of each cutting edge respectively. In addition, Li et al. [8] simulated the cutting force in the helical milling process, and described the surface topology and surface quality of hole-making. Through the study on the helical milling of aviation aluminum alloy, Li et al. [9] calculated the instantaneous uncut chip thickness (IUCT) with high precision considering the cutter runout effect, the dual mechanism force model was adopted to predict cutting forces in the 
helical milling process. Araujo et al. [10] mainly considered the geometric shape of the tool and its tridimensional tool trajectory, analyzed the change of cutting force in thread milling process, which was similar to helical milling process.

In order to improve hole-making quality, the tilted helical milling technology was proposed using ball end mill[11], the kinematic and cutting principle were discussed respectively, but sound mechanics model had not been developed. The cutting force modeling of ball-end milling is more complicate, the main reason is that the spherical surface of ball-end cutters participates in the cutting process and is not equivalent to end-milling cutters. Yucesan [12] and Altintas [13] carried out an in-depth analysis of the mechanical dynamics of the milling process performed by ball-end cutters, analyzed the change of cutting force in the time domain, considered the instantaneous regenerated chip load and force coefficients, and established cutting force model. Jia et al.[14] introduced interaction between material properties and machining conditions, presented a novel ball-end milling force prediction model. Wojciechowski et al. [15]proposed an accurate cutting force model applied for the finishing ball end milling, including the influence of surface inclination and cutter's run out. The result showed that the relative error was reduced from $16 \%$ to $7 \%$. Ball head milling cutter is mainly used in surface machining, the focus of the research lies in that the analysis of the non-deformable chip thickness in the surface machining process and the change of the cutter's contact area, and for the ball helical milling process, it is also important to discuss the change of the contact area.

In the ball helical milling process, axial feed is simultaneously completed when the tool lies in the cutting process, then axial force is far greater than cutting force in other directions. In addition, due to the special characteristics of the ball-end cutter, the main contact area between the tool and the workpiece material is mainly the spherical cutting edge, so during the helical milling process, along with the axial feed, the instantaneous tool cut-in angle, cut-out angle, chip thickness and contact area change from time to time. Therefore, the construction of the cutting force model in the ball helical milling process is particularly difficult. It is necessary to first calculate the relative position parameters of the tool and workpiece, and then determine the instantaneous chip thickness, which are summed up to obtain the instantaneous milling load of the ball end mill. Based on the basic machining principles of helical milling and the geometry of ball-end cutters, this paper considers the tool movement and material removal during cutting process, integrates mechanical principle to establish a relatively accurate cutting force model for ball helical milling process.

\section{Kinematics of helical milling}

\subsection{Kinematic analysis}

In order to analyze the tool movement in detail in the helical milling process, three coordinate systems are set up, there are respectively the cutting edge coordinate system, tool coordinate system and workpiece coordinate system. A tool coordinate system(TCS) $\mathrm{O}_{2} x_{2} y_{2} z_{2}$ and workpiece coordinate system(WCS) $O_{1} x_{1} y_{1} z_{1}$ are respectively established first, as shown in Fig.1. In the tool coordinate system, the tool rotation axis is taken as the $z_{2}$ axis in the TCS, the vertical upward direction is the positive direction, at the same time, the upper plane of the workpiece is taken as the starting point of the $z$-axis in the TCS and WCS, and the vertical upward direction is the positive direction. The cutting tool begins to cut in the cutting edge coordinate system $\mathrm{O}_{2} x y z$, in which rotational angle of the reference flute $\theta$ is positive in clockwise direction and measured from $x$-axis, the 
cutter rotates counterclockwise to complete the orbital revolution with $\phi$, as shown in Fig.1.

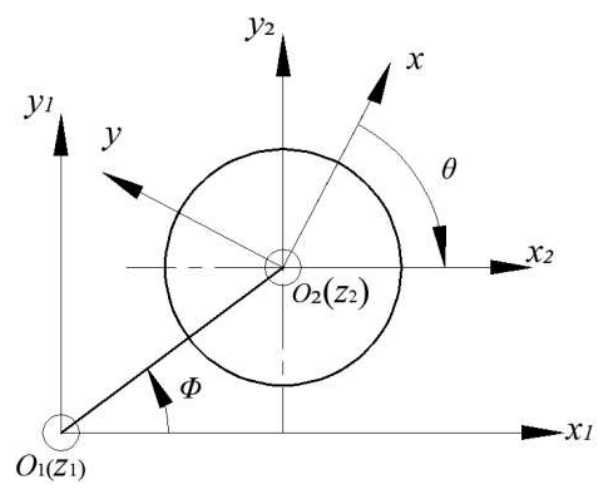

Fig.1 Coordinate system

In the helical milling process, due to the complex movement of the ball end cutter, the track of tool center is helical line, as shown in Fig.2. Then in the plane of $X O Y$, the cutting tool orbits counterclockwise on the basis of clockwise rotation, the parameters will meet follow relationships.

$$
\theta_{j}(t)=\theta_{j 0}+2 \pi n t / 60
$$

$$
\phi(t)=\phi_{0}+2 \pi n_{r} t / 60
$$

The axial feed rate of the tool $s_{a}$ is

$$
s_{a}=\frac{a_{p} \cdot n_{r}}{N \cdot n}
$$

Feed rate in the tool center $S_{t}$ is

$$
s_{t}=\frac{\pi \cdot n_{r}\left(D_{h}-D_{t}\right)}{n \cdot N}
$$

In addition, as shown in Fig.2, although the tool is perpendicular to plane $x o y$, because of the existence of the helical angle, the tool cutting edge is not perpendicular to the plane $X O Y$, the material removal is spherical cutting edge to finish first in the milling process, unlike vertical milling cutter, the ball head milling cutter has not obvious side edge and bottom edges, but spherical cutting edge needs to be done two movements at the same time, material removal is done by the spherical cutting edge.

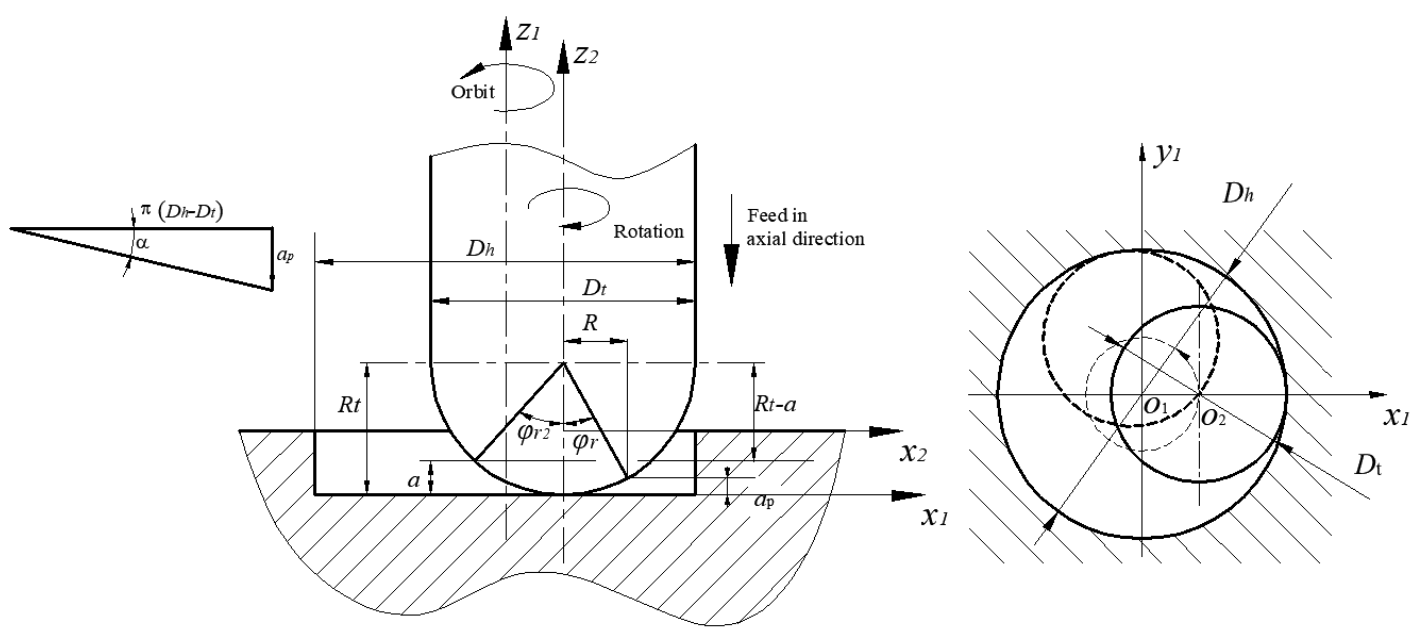

Fig. 2 Cutting principle of helical milling process

That is to say, in fact, it is characterized by a simultaneous movement of the tool on a circular path and a superimposed movement in the axial direction, the superposition of circular and axial feed is actually helical feed, which is different to the only peripheral or frontal feed.

\subsection{Geometry of ball end cutter}

Point $P$ on the cutting edge of the ball head is shown in Fig. 3, there are tri-directional micro-elements cutting forces at this point. Assuming that the cutting forces are tangential, radial and axial micro-elements respectively, they are expressed as $d F_{t}, d F_{r}$ and $d F_{a}$, where $t$-direction points along with the direction of cutting speed, the $a$-direction follows the right hand rule, the $r$-direction points to the center of the ball, and the directions of the cutting forces of tri-directional micro-elements are shown in Fig.3. 

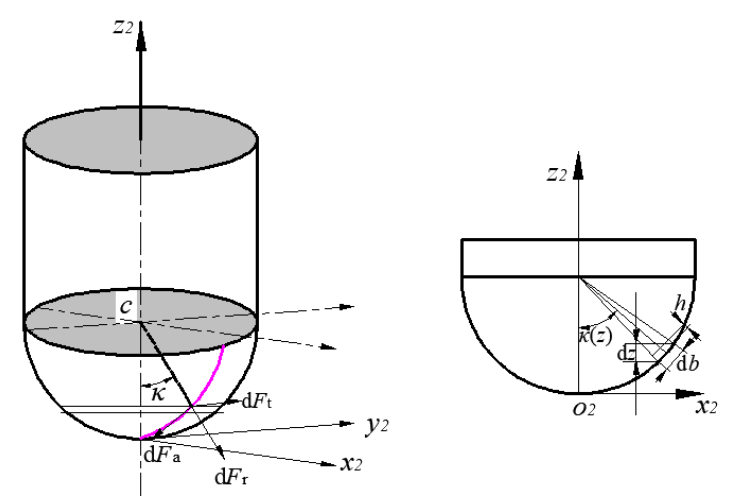

Fig.3 Geometric model of the ball end cutter

The generalized geometric model for ball-end cutter was presented by Altintas et al.[16-17]. The ball end mill has both spherical and cylindrical body, and the cutting edges are usually helical, axial position angle $\kappa$ within the arc zone varies along the cutter axis, and it is a very important parameter. The flutes of the ball end mill meet at the tip of the sphere, and are ground with a constant helix lead. Due to reduction of radius at xoy plane to ward the ball tip in the axial direction, the local helix angle along the cutting flute varies for constant helix-lead cutters. The helix, rake and lag angles at the hemispherical section vary due to the increasing diameter along its axis. The cutter with constant lead is taken as a base model, then

$$
x^{2}+y^{2}+\left(R_{\mathrm{t}}-z\right)^{2}=R_{t}^{2}
$$

The cutter radius $R$ in $x o y$ plane at axial location $z$ is

$$
R(z)=R_{t} \sqrt{1-\left(1-\frac{z}{R_{t}}\right)^{2}}
$$

The ball part of the cutter meets with a cylindrical shank, helix angle $i$ at any position in the spherical surface is

$$
\tan i(z)=\frac{R(z)}{R_{t}} \tan i_{0}
$$

Due to the influence of helix angle, the points on a flute do not contact with the work material at the same time. Then the position angle $\kappa$ of a point on the flute can be expressed as

$$
\kappa(z)=\sin ^{-1}\left(\frac{R(z)}{R_{t}}\right)
$$

All of these parameters are functions of the height, it will be zero at the ball tip part. Each flute is ground with constant radial rake and clearance angles.

\subsection{Variation of undeformed chip thickness and} contact area

In the mechanistic model, the cutting forces are usually assumed to be proportional to the undeformed chip thickness. In the ball helical milling process, the numbers of cutting edge involved in the processing gradually increase, when cutting depth is fixed, the axial position angle of the spherical cutting edge is constant, if cutting depths change, cutting forces are considered as the function of axial position angle. In order to observe the cutting state of the ball helical milling process, especially in the initial cutting stage, the contact part of the tool and the workpiece starts from the tip of the cutting head, the spherical cutting edges of different heights gradually participate in the cutting, and the cutting depth gradually increases with the increase of the cutting width, as shown in Fig.4. The state of tool cutting into the workpiece is illustrated in Fig. 4(a), it can be seen that contact zones increase gradually, until spherical cutting edges completely enter the cutting state. The state in Fig.4 (b) is just reverse, spherical cutting edges are gradually cutting out of the cutting state. 

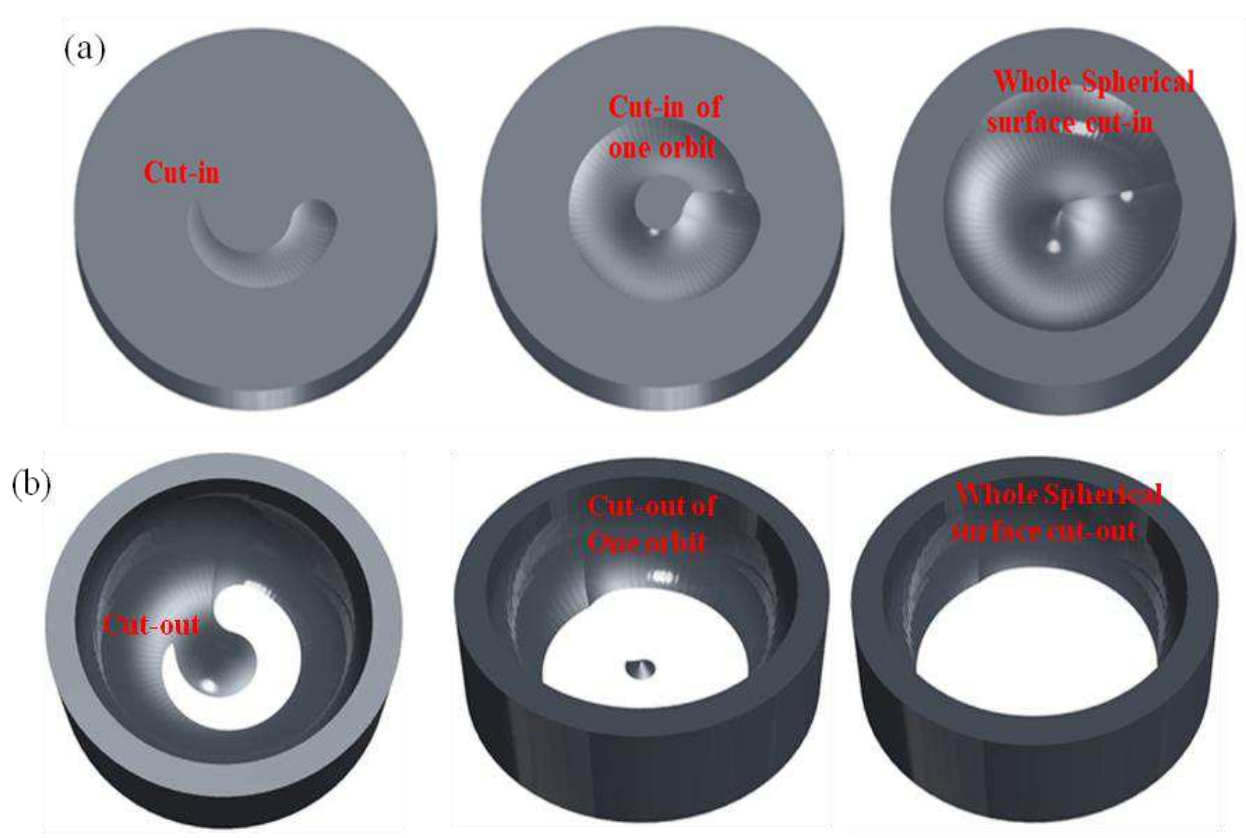

Fig. 4 Cutting state in different times:(a) entry zone; (b) exit zone

Whole cutting state in Fig.4 shows that spherical cutting edges participate in and out of the cutting process gradually, the direct reflection is the cutting forces increase gradually. For pure horizontal feed, the contribution of points near the tool tip to chip thickness generation is almost negligible; however for pure vertical feed, the contribution from those points is significant[14]. In order to obtain a steady cut while plunging with a ball end mill, ball part of the tool has to engage with the workpiece from tool tip to ball cylindrical part transition level, once entire ball part engages with the workpiece, engagement conditions do not change in the following feed movements of the cutter, and cylindrical part does not contribute to cutting.

\section{Modeling of cutting forces}

The ball-end cutter completes a certain amount of axial feed for each helical rotation (orbital rotation) around the center of the pre-machined hole. According to the kinematic analysis of the contact area, it is known that the material removal process is more complicated, which is obviously different from that of the end mill. Therefore, the cutting force modeling process needs to be adjusted according to the actual situation, and it must be considered separately for the circumferential feed and the axial feed of spherical cutting edges.

\subsection{Modeling of microelement cutting forces}

In order to calculate the relatively accurate cutting force during ball helical milling process, the cutter is divided into axial disc elements of height $d z$ where orthogonal to oblique transformation is implemented, and the surface cut by the helical ball end mill slice at each axial level is digitized by a number of points, and stored in Cartesian coordinates system. According to the principle of orthogonal cutting, assuming that the point is located on the first cutting edge and its axial height is $z$, the differential geometry method is used to discrete the tool into several axially distributed microelements, the differential forces in radial, tangential and axial directions[18-19] are expressed by:

$$
\left\{\begin{array}{l}
\mathrm{d} F_{t i}(\theta, z)=K_{t c} h_{i}(\theta, z) \mathrm{d} b+K_{t e} \mathrm{~d} S \\
\mathrm{~d} F_{r i}(\theta, z)=K_{r c} h_{i}(\theta, z) \mathrm{d} b+K_{r e} \mathrm{~d} S \\
\mathrm{~d} F_{a i}(\theta, z)=K_{a c} h_{i}(\theta, z) \mathrm{d} b+K_{a e} \mathrm{~d} S
\end{array}\right.
$$

For ball end mill, the uncut chip thickness normal to the cutting edge will vary with the position of the cutting point according to regenerated surface. The differential width is the projected length of an 
infinitesimal cutting flute in the direction along the cutting speed, while chip width can be found using differential cutting edge height and axial position angle, the un-deformed chip width can be expressed as follows:

$$
\mathrm{d} b=\mathrm{d} z / \sin \kappa
$$

Length of the edge discrete element $\mathrm{d} S$ can be known from the geometry of the cutting tool

$$
\mathrm{d} S(z)=\mathrm{d} z \sqrt{\left(r(z) \psi^{\prime}(z)\right)^{2}+\left(r^{\prime}(z)\right)^{2}+1}
$$

For ball-end cutters, the effective radius $r$ involved in the cutting process is

$$
r(z)=R_{t} \sin \kappa(z)
$$

Since there is a spherical helix, the following formula exists for the arc length of the cutting

$$
\mathrm{d} S(\kappa)=R \sqrt{\left(1+\sin ^{4} \kappa \tan ^{2} \alpha\right)} \cdot \mathrm{d} \kappa
$$

In addition, the instantaneous cross angle at the axial depth $z$ between the cutter tooth and the workpiece can be expressed as

$$
\theta_{j}(t)=\theta_{1}(t)+(i-1) \frac{2 \pi}{N}-\psi(z)
$$

When the axial depth of cut is $z$, due to the influence of helix angle $i$, a point on the cutting edge will lag

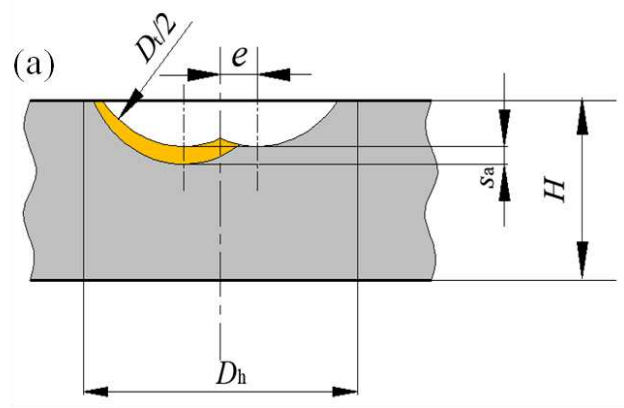

Fig. 5 Schematic diagram of helical milling process: (a) local cuts,(b) fully involved

It can be seen that at different times, the size of the removed material is different, but the biggest thickness at the bottom end does not change, which is equal to the axial depth of cut, and the chip width is equal to the effective cutting radius of the tool involved. The radius is different at different time. When the part of the spherical surface is cut in the 8

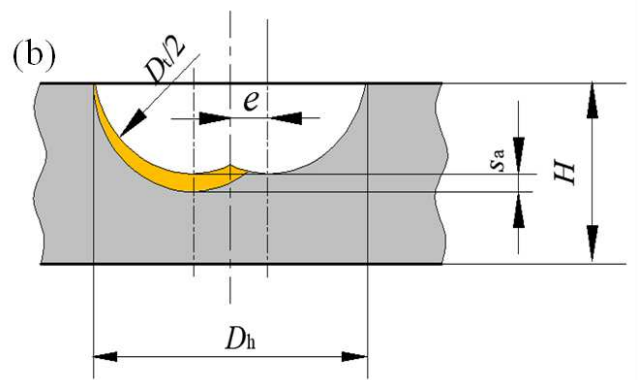

behind the upper end of the cutting edge, the lag angle $\psi$ can be calculated as

$$
\psi(z)=(1-\cos \kappa) \times \tan i
$$

Namely, when $z=0, \psi(z)=0$, helix angle does not affect the rotation angle $\theta$. The cutter radius $R(\mathrm{z})$, the rotation lag angle $\psi(z)$, and the axial immersion angle $\kappa(z)$ of point $P$ are important parameters for identifying the cutting force.

\subsection{Analysis of the cutting process}

In the ball end milling process, when the cutter completes the plane feed, the cutting depth does not change, and the position angle remains constant within a certain range. Only the three-way cutting forces caused by the periphery feed in the spherical area is considered[12]. But during the ball helical milling process, the tool needs to complete a helical feed, then the scope of position angles changes at each moment. The position angles vary from 0 to 90 degrees, and the cutting depth keeps changing. That is, the tool position is changing. Since the axial depth of cut per revolution is constant, two typical moments in the cutting process are considered, as shown in Fig.5.

cutting state, as shown in Fig. 5(a), effective the radius is smaller than tool radius, when the spherical surface of tool is fully involved in the cutting state, as shown in Fig. 5(b), the axial spherical chip is the largest, then it will maintain until the tool penetrates the bottom surface of the workpiece, and the thickness of the axial chip gradually decreases to zero. Namely, the 
cross-sectional area of the removed material is different with same axial feed, which is related to the axial position angle. In addition, due to the axial advance of the tool, the undeformed chip thickness is a function of the position angle.

\subsection{Undeformed chip thickness}

(a)

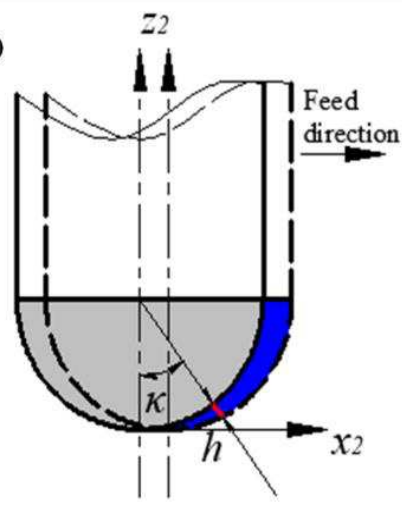

During the ball helical milling process, while the tool completes the transversal feed in the xoy plane, it maintains a certain feed rate in the axial direction. The feed of the cutting edge in different directions will cause different undeformed chips, as shown in Fig.6.

(b)

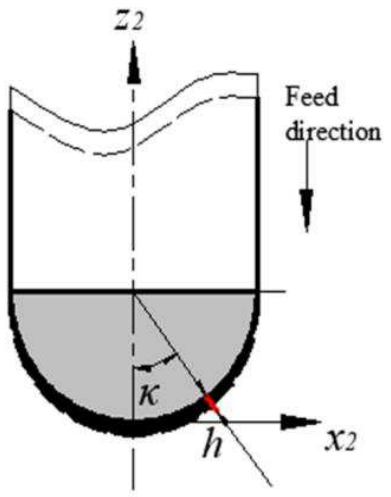

Fig.6 Undeformed chip thickness in different directions: (a) transversal feed;(b) axial feed

When the tool feeds in the transversal direction, the feed of the tool can be referred to the general ball end mill[18], as shown in Fig.6(a), the chip thickness $h_{j r}$ can be expressed as classic formula. For general ball end milling process, usually not the entire sphere is in the cutting area, undeformed chip thickness can be approximated in terms of as

$$
h_{j r}(\theta, \kappa)=s_{t} \sin \theta_{j}(t) \sin \kappa(z)
$$

Due to the existence of the spherical surface, the undeformed chip shape is a parameter related to the position angle when the axial feed exists, as shown in Fig.6(b), the undeformed chip thickness in the xoz plane $h_{j z}$ is

$$
h_{j z}(\kappa)=s_{a} \cos \kappa(z)
$$

Feed rate in axial direction:

$$
s_{a}=a_{p} \cdot n_{r}
$$

That is, when the axial position angle is equal to $90^{\circ}$, the undeformed chip thickness in the axial direction is zero, and when the axial position angle is equal to $0^{\circ}$, the axial undeformed chip thickness is the largest in the center of the spherical surface. It can be seen that the chip shape and thickness in both directions will change with the change of axial position angle. The instantaneous undeformed chip thickness will be influenced by the transversal and axial feed motion. As shown in Fig.7, the axial feed motion along with the reverse $z$-direction will increase the undeformed chip thickness, it is assumed that the initial position of the spherical element of the tool is $O$, and the final position is $O_{2}$, which is actually the combination of axial feed and peripheral feed, it is assumed that $M_{1} N_{1}=M_{2} N_{2}$, then the final chip thickness can be expressed in terms of $M_{2} P$, which is expressed as

$$
M_{2} P=M_{2} N_{2}+N_{2} P
$$



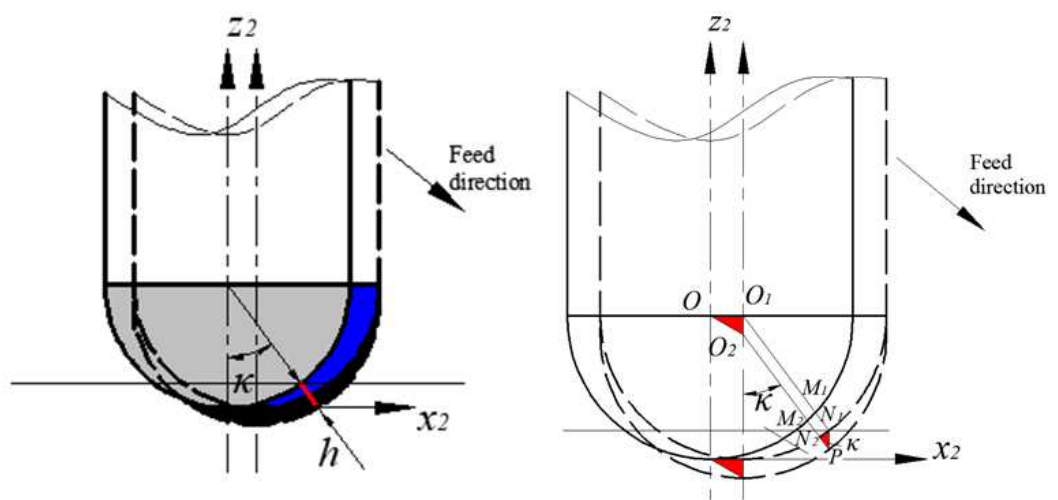

Fig.7 Determination of undeformed chip thickness

Due to ball end mill complete circumferential and axial feeds in the helical milling process, so total chip thickness $h_{j}$ can be calculated as

$$
h_{j}(\theta, \kappa)=s_{t} \sin \theta_{j}(t) \sin \kappa(z)+s_{a} \cos \kappa(z)
$$

Axis position angle $\kappa$ is not constant, especially at the beginning of the machining stage, the value $\kappa$ is small, then gradually increase, until the sphere completely lies in the cutting area, when the processing depth is more than $R_{t}$, the whole sphere is in cutting condition, the cutting area is the largest, and keeps to reach the maximum cutting force, cutting forces are bigger than the initial stage and the end stage, therefore, in order to analyze convenient, stable cutting stage will be chosen to the basis of analysis follow-up. The changeable scope of axial position angle $\kappa$ lies in

$$
0 \leq \kappa \leq \pi / 2
$$

In principle, the two extreme cases can be calculated directly, when $\kappa=0^{\circ}$ and $\kappa=90^{\circ}$, the undeformed chip thickness reflects only one part of the circumferential feed or axial feed respectively. In the axial direction, the relation between the axial feed rate and mean axial force needs to be directly considered.

Namely, the precise calculation of the cutting zone is particularly important for the analysis of the cutting process and force calculation

\subsection{Transformation of cutting force}

The initial analysis of the cutting force is performed in the coordinate system of the tool tooth, and then through the coordinate transformation to the tool coordinate system, and to complete the corresponding calculation, the cutting forces need to be converted into the workpiece coordinate system. In general, for the ball end milling cutter, cutting force in $x$ and $y$ direction will be related to $t, r, a$ direction, force in $z$ direction is only related to $r$ and $a$ directions. It is considered to be a cutting edge that completes both circumferential and axial feed. The thickness of undeformed chips is considered respectively.

$$
\left\{\begin{array}{c}
h_{j 1}(\theta, \kappa)=s_{t} \sin \theta_{j}(t) \sin \kappa(z) \\
h_{j 2}(\theta, \kappa)=s_{a} \cos \kappa(z) \\
\kappa_{i}=i \cdot d \kappa
\end{array}\right.
$$

Where $d \kappa$ is the discrete interval and $i$ is the index of discrete element.

In a stable stage, the cutting is discontinuous process, the cutting blade participating in the cutting is not the same in different cutting position, there will be cut-in and cut-out process, namely, the axial cutting zone is a circular area, different to the end mill, and in the xoy plane, just like before, the axial force needs to be considered separately. Then considering the helix angle, cutting forces in the xoy plane and perpendicular direction can be calculated as 


$$
\left[\begin{array}{l}
\mathrm{d} F_{x c i}\left(\theta_{i}, z\right) \\
\mathrm{d} F_{y c i}\left(\theta_{i}, z\right) \\
\mathrm{d} F_{z c i}\left(\theta_{i}, z\right)
\end{array}\right]=\left[\begin{array}{ccc}
\cos \alpha & 0 & 0 \\
0 & \cos \alpha & 0 \\
-\sin \alpha & -\sin \alpha & 1
\end{array}\right] \times\left[\begin{array}{l}
\mathrm{d} F_{x i}\left(\theta_{i}, z\right) \\
\mathrm{d} F_{y i}\left(\theta_{i}, z\right) \\
\mathrm{d} F_{z i}\left(\theta_{i}, z\right)
\end{array}\right]
$$

The cutting force on the $i$ th cutting edge can be obtained by integrating the axial height of the tool as

$$
\left\{\begin{array}{l}
\mathrm{d} F_{x c i}\left(\theta_{i}\right)=\int_{z 1}^{z 2} \mathrm{~d} F_{x c i}\left(\theta_{i}, z\right) \\
\mathrm{d} F_{y c i}\left(\theta_{i}\right)=\int_{z 1}^{z 2} \mathrm{~d} F_{y c i}\left(\theta_{i}, z\right) \\
\mathrm{d} F_{z c i}\left(\theta_{i}\right)=\int_{z 1}^{z 2} \mathrm{~d} F_{z c i}\left(\theta_{i}, z\right)
\end{array}\right.
$$

The uncut chip thickness normal to the cutting edge will vary with the position of the cutting point according to regenerated surface. The cutting force can be calculated separately for each infinitesimal element, total cutting forces are the sum of all infinitesimal element force. The total cutting force of engagement area can be expressed as follows:

$$
\left[\begin{array}{c}
F_{x c} \\
F_{y c} \\
F_{z c}
\end{array}\right]=\int_{\theta_{s t}}^{\theta_{e x}} \int_{\kappa_{\min }}^{\kappa_{\max }}\left[\begin{array}{l}
\mathrm{d} F_{x c} \\
\mathrm{~d} F_{y c} \\
\mathrm{~d} F_{z c}
\end{array}\right] \mathrm{d} \theta \mathrm{d} \kappa
$$

In the ball helical milling process, the engagement conditions between the cutter and the workpiece determines the chip thickness, the angles at which the cutter enters and leaves the cutting zone at each axial level along the cutter axis. These geometric parameters are used to calculate cutting forces at each tool rotation angle, where $\theta_{s t}=0, \theta_{e x}=\pi$ and $\kappa_{\min }=0, \kappa_{\max }=\pi / 2$.entry and exit angles

For the ball helical milling process, the cutting force of the tool is not only related to the rotation angle of the tool, but also related to the orbital angle of the tool and the axial position angle. Because the evaluation and measurement of the cutting force ultimately needs to be performed in the workpiece coordinate system, so the total cutting forces acting on the cutter in $\mathrm{x}-\mathrm{y}-\mathrm{z}$ directions are obtained by summing the contribution of each flute

$$
\left\{\begin{array}{c}
F_{x}(\theta, \phi)=\sum_{i=1}^{N} g\left(\theta_{i}\right)\left[F_{x c i} \cos \phi+F_{y c i} \sin \phi\right] \\
F_{y}(\theta, \phi)=\sum_{i=1}^{N} g\left(\theta_{i}\right)\left[-F_{x c i} \sin \phi+F_{y c i} \cos \phi\right] \\
F_{z}(\theta, \phi)=\sum_{i=1}^{N} g\left(\theta_{i}\right) F_{z c i}
\end{array}\right.
$$

Since milling is an intermittent operation, angular position of flutes needs to be known to check whether the flute is in or out of the cutting at any instant, so $g\left(\theta_{i}\right)$ is a special parameter used to show if the tool is in the cut or not, when the tool is in cut, $g\left(\theta_{i}\right)=1$, otherwise $g\left(\theta_{i}\right)=0$. Where $\phi$ changes from 0 to $2 \pi$.

In order to remove material, there must be a relative motion between the tool and the workpiece. Since the surface speed (cutting speed) at the tool tip is zero, and the work material is fixed, cutting does not take place. On the other hand, the cutting tool is forced to provide plastic deformation even at the tip point; therefore the desired deformation is realized by indentation (penetration) of the tool instead of cutting[20]. However, the indentation effect is not included in the existing cutting force model, the indentation force depends on axial feed speed. By reporting the gap between simulated and experimental axial forces in relation to the feed speed, it is possible to identify the coefficients of the model, the following relation is obtained:

$$
F(z)=K_{z} s_{a} R_{h}
$$

Namely, the relationship between axial feed rate and indentation force is established, where $s_{a}$ is axial feed rate, $R_{h}$ is hole-making radium, due to the hole-making diameter is fixed, so the indentation force is only related to the axial feed rate, axial cutting coefficients $K_{z}$ can be received through the linear 
fitted to the average axial force. Thus the final cutting forces model in ball helical milling process is illustrated as follows:

$$
\left\{\begin{array}{c}
F_{x}(\theta, \phi)=\sum_{i=1}^{N} g\left(\theta_{i}\right)\left[F_{x c i} \cos \phi+F_{y c i} \sin \phi\right] \\
F_{y}(\theta, \phi)=\sum_{i=1}^{N} g\left(\theta_{i}\right)\left[-F_{x c i} \sin \phi+F_{y c i} \cos \phi\right] \\
F_{z}(\theta, \phi)=\sum_{i=1}^{N} g\left(\theta_{i}\right) F_{z c i}+F(z)
\end{array}\right.
$$

\section{Cutting experiments setup}

\subsection{Experiment conditions}

The material used in the test was Ti6Al4V plate with $120 \mathrm{~mm} \times 120 \mathrm{~mm} \times 10 \mathrm{~mm}$. Three-factor and three-level experiments were carried out in the machining center, the two edges ball end mill with TiAlN coating based on cemented carbide was used, the diameter was $6 \mathrm{~mm}$ with $35^{\circ}$ helix angle and normal rake angle of $0^{\circ}$ on ball part, cutting forces and torque were measured in the $x, y$ and $z$ directions using 3-direction Kistler 9119AA2 table type dynamometer, as shown in Fig.8.
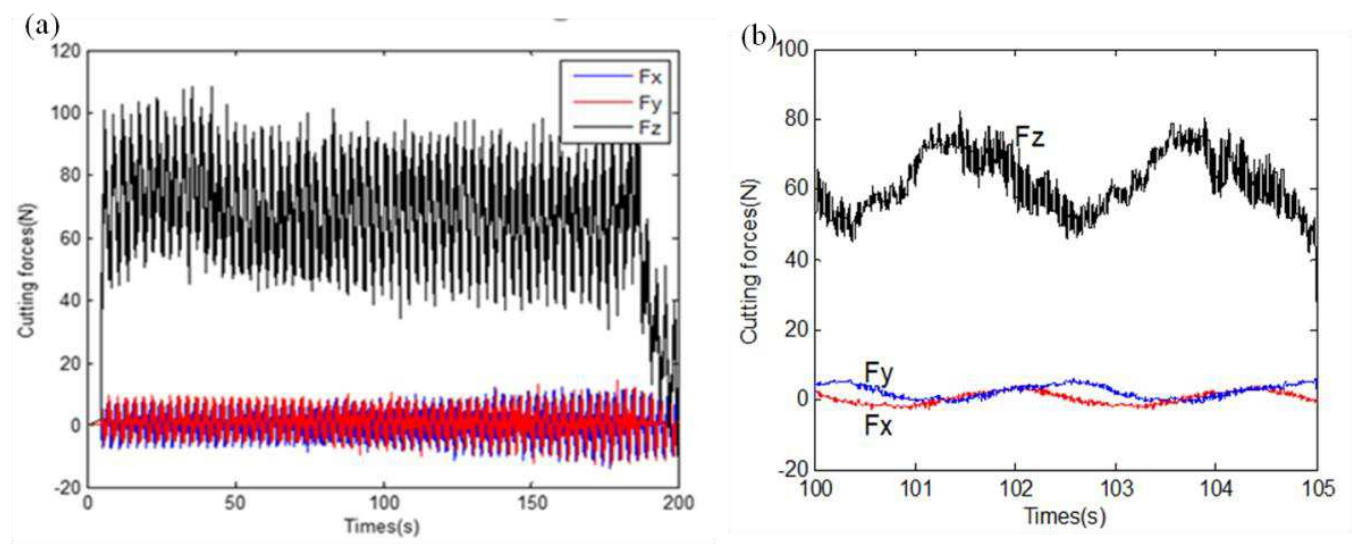

Fig. 9 Cutting force data obtained from experiments: (a)original forces;(b) filtered forces

It can be seen from Fig.9 (a) that the $x y$-direction cutting forces show clear change from small to large. The reason lies in the cutting edges of ball end mill

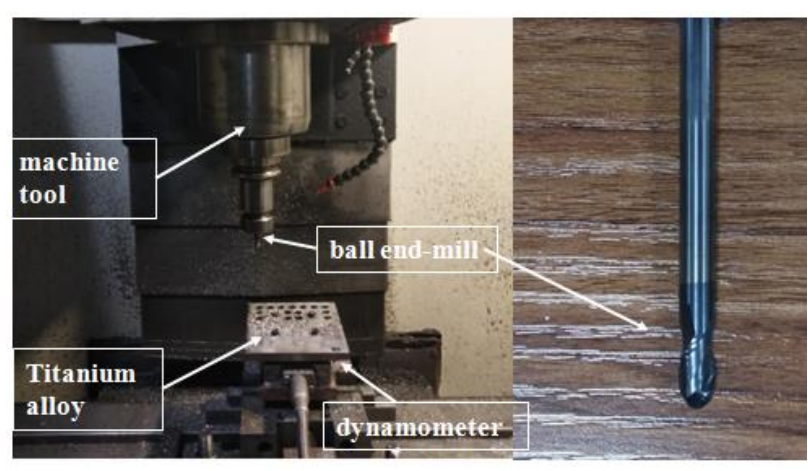

Fig.8 Cutting experiment

Representative values of its variation were calculated and analyzed as response of the experiments, the related cutting parameters are illustrated in Table 1.

Table 1 Cutting parameters

\begin{tabular}{cccc}
\hline \multirow{2}{*}{ Factors } & \multicolumn{3}{c}{ Levels } \\
\cline { 2 - 4 } & 1 & 2 & 3 \\
\hline Cutting speed(m/min) & 60 & 70 & 80 \\
Feed rate(mm/t) & 0.04 & 0.05 & 0.06 \\
Depth of cut(mm/rev) & 0.1 & 0.15 & 0.2 \\
\hline
\end{tabular}

\subsection{Analysis of experiment results}

\subsubsection{General trend of cutting forces}

When the cutting speed is $60 \mathrm{~m} / \mathrm{min}$, the feed rate is $0.04 \mathrm{~mm} /$ tooth, and the axial depth of cut is 0.1 $\mathrm{mm} / \mathrm{rev}$, three-axis cutting forces are illustrated in Fig.9(a), and the filtered values(after $50 \mathrm{~Hz}$ ) are showed in Fig.9(b).

gradually enter the cutting state, the effective cutting radius of the participating cutting tools gradually increases, so the cutting force also shows the same 
change. When the cutting edges are fully involved into cutting, the cutting forces will reach their peak value, then the cutting forces will keep the state until cutting out of the process. When the tool cuts near the through hole, the thickness of the remaining material is lower than a certain value, and the give up phenomenon of the tool will occur. The manifestation is that the support rigidity of the bottom material to the milling cutter becomes smaller, and the cutting force and torque gradually reduce until the milling is completed. It also can be seen from the figure that the forces in $x$ and $y$ directions are far lower than the axial direction. The axial cutting force fluctuates greatly. The main reason for this phenomenon maybe lies in that the selected ball-end cutter is a two-edge cutting tool, the $x$ and $y$ direction cutting forces are mainly related to the radial feed rate. When rotation speeds are same with same feed rate per tooth in the helical milling process with four-edges end mill[2], the revolution speed is half for the two-edge compared to the four-edge tools, then the cutting forces in the $x$ and $y$
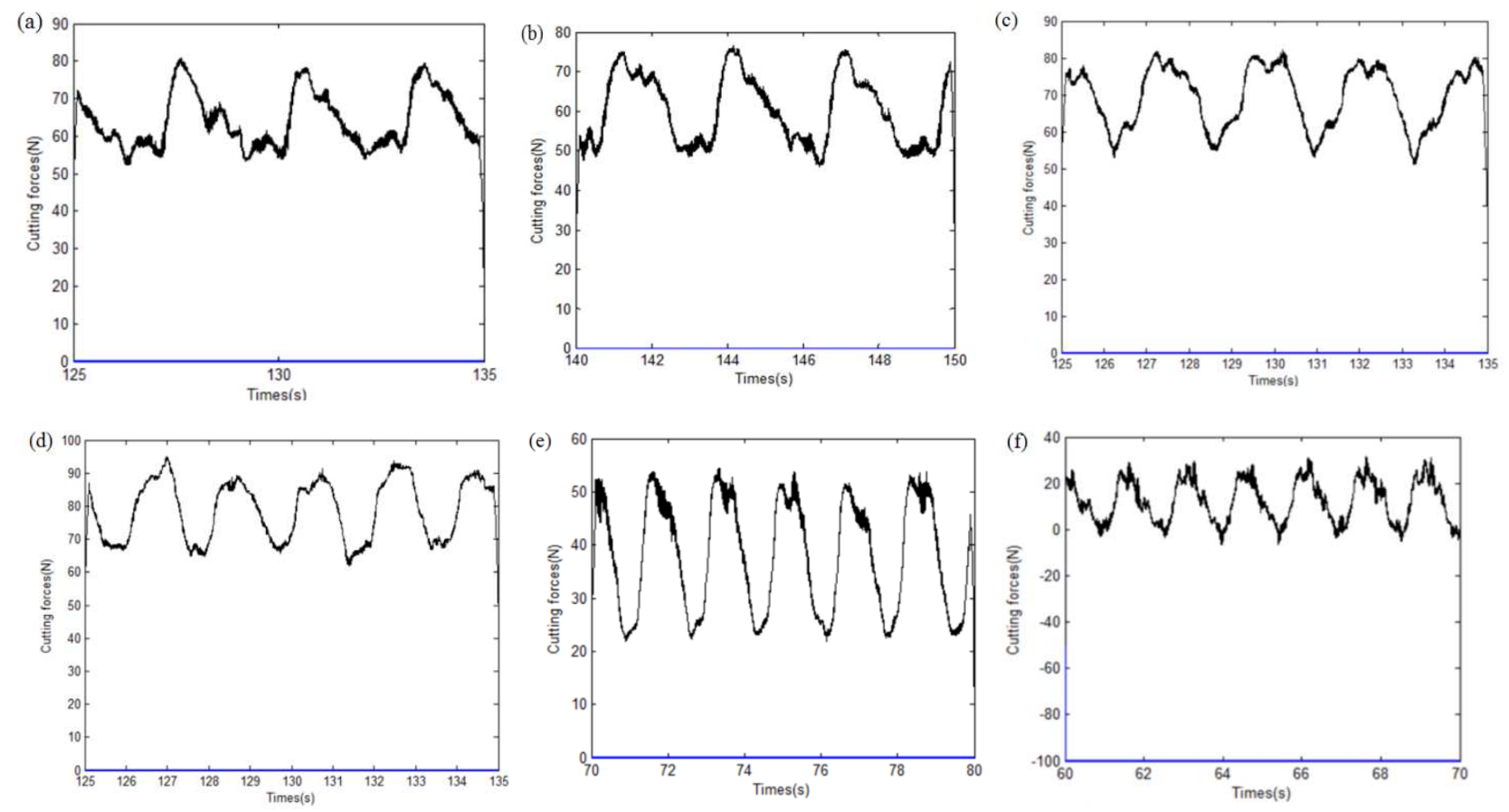

Fig.10 Axial cutting forces

directions decrease into the half, while because the feed rate in the axial direction has not changed, the cutting force value in the $z$ direction does not change. For a two-edge ball end mill, the fluctuation of the cutting force in the $z$ direction is big due to the influence of the position angle, which is very different to the end mill, but the degree of tool wear will be significantly reduced.

\subsubsection{Axial cutting force}

As can be seen from the experimental results, when the ball end milling cutter is used to complete the milling process, due to the influence of the ball head position, the axial cutting forces present different variation rules, as shown in Fig.10, where the variation of axial cutting force with processing time under different cutting parameters (10S for all), it can be seen that, on the whole, axial cutting forces present obvious fluctuation phenomenon, the corresponding cutting parameters and results are illustrated in Table 2. 
obviously different, but the frequencies of the wave are not affected, and according to the Fig. 10(c) and (d), only feed rates are different, but the cycles have changed, and according to the Fig. 10(a) and (d), the cycles are different, the impact of feed rate is bigger, and then according to the Fig.10 (d) and (e), cutting speed has the influence to cycle. That is to say, the effect of the axial cutting depth on the fluctuation of the axial force can be ignored, and the effect of feed rate and cutting speed on the axial cutting force must be considered. Then the main analysis should be placed on these two cutting parameters.

Table 2 Cutting parameters corresponding to Fig.10

\begin{tabular}{cllllll}
\hline & (a) & (b) & (c) & (d) & (e) & (f) \\
\hline Cutting speed(m/min) & 60 & 60 & 60 & 60 & 70 & 70 \\
Feed rate(mm/t) & 0.04 & 0.04 & 0.05 & 0.06 & 0.06 & 0.06 \\
Depth of cut(mm/rev) & 0.1 & 0.15 & 0.1 & 0.1 & 0.1 & 0.15 \\
Change of axial direction force(N) & $55-80$ & $50-75$ & $55-80$ & $67-90$ & $50-80$ & $22-52$ \\
Number of cycle & 3.5 & 3.5 & 4.5 & 5.5 & 6 & 6
\end{tabular}

spherical cutting edge, therefore, it can not simply to

From Eq. 4, it can be seen that

$$
n_{r}=\frac{s_{t} \cdot n \cdot N}{\pi \cdot\left(D_{h}-D_{t}\right)}
$$

When the tool and hole-making diameter are determined, the speed of revolution can be converted to the angle of revolution

$$
\phi=2 \pi \cdot n_{r} \cdot t / 60
$$

Namely, changes in cutting speed and feed rate can be directly converted to revolution speed. In other words, the axial force is related to the revolution angle of the tool and is a function of the revolution angle, which is same as reference[7], where showed that axial force signals are periodic with different frequencies, the forces applied on the axial part of the tool are variable, with a frequency equal to the tool revolution frequency in the helical milling of titanium alloy.

The main reason lies in that in the traditional helical milling process, the tool is similar as end mill, the side edge and bottom edges are considered separately, the work of two different kinds cutting edge is different in the cutting process, but for the ball milling cutter, whatever lateral feed and the axial feed, cutting and feeding process are completed by distinguish side edge and bottom edge separately in the analyse process, while fully consider the ball milling cutter.

\subsubsection{Modification of cutting force model}

According to the experimental results, considering the additional axial force caused by the axial feed, the axial cutting force is also directly related to the angle of revolution. Through the analysis of the experimental results, the model of the cutting force is adjusted as follows:

$$
\left\{\begin{array}{c}
F_{x}(\theta, \phi)=\sum_{i=1}^{N} g\left(\theta_{i}\right)\left[F_{x c i} \cos \phi+F_{y c i} \sin \phi\right] \\
F_{y}(\theta, \phi)=\sum_{i=1}^{N} g\left(\theta_{i}\right)\left[-F_{x c i} \sin \phi+F_{y c i} \cos \phi\right] \\
F_{z}(\theta, \phi)=\sum_{i=1}^{N} g\left(\theta_{i}\right) F_{z c i} \sin \phi+F(z)
\end{array}\right.
$$

Because spherical cutting edges perform both axial and tangential feed in the ball helical milling process, there is no evidence of tangential and axial direction, so in the process of cutting force model, just for the sake of more clarity, the cutting force model is adjusted and corrected as illustrated in Eq.31.

\section{Identification of cutting force coefficients}

The key in the modeling of cutting forces is to identify the cutting force coefficients accurately. Cutting force 
coefficients for ball end mill are generally considered to be the function of the position angle when the average force coefficient identification method is used. While in the helical milling process, although the tool must complete the axial feed on the basis of rotation and revolution, the axial depth of cut per revolution is relatively small, but in the single-factor slot test, the usual cutting depth is relatively large. Gradisek[21] discussed when the depth of cut for the ball end mill was lower than $0.3 \mathrm{~mm}$, smaller radial immersions yielded larger coefficients than larger immersions, while for the depth of cut was bigger than $0.3 \mathrm{~mm}$, the situation was reversed. In the helical milling process, axial depths of cut lie in $0.1-0.3 \mathrm{~mm} / \mathrm{r}$, and the tool always keeps axial feed state, the slot test is not completely suitable for the identification of the cutting force coefficient, the change of cutting forces coefficients need to be considered detailedly.

There are six coefficients including the cutting force coefficients $K_{t c} 、 K_{r c}$ and $K_{a c}$, edge force coefficients $K_{t e} 、 K_{r e}$ and $K_{a e}$ in the Eq.9, the identification of cutting force coefficients is the key problem in modeling of the cutting forces. But due to the different action of two kinds of cutting force coefficients, they need to be analyzed respectively. In the averaged method, a series of milling tests are the necessary, while in the instantaneous method, if cutting force coefficients are constant, the identification can be completed through only one cutting experiment, but if the coefficients are not constant, the identification need to be done according to the change of cutting parameters.

Feed rate in both circumferential and axial directions are very small, in fact, the cutting force coefficient will decrease with the increase of undeformed chip thickness, when the chip thickness increases to a certain range, the cutting force coefficients are constant, the undeformed chip thickness can be expressed as the function of feeding rate, namely, undeformed chip thickness is directly represented feeding rate, and cutting force coefficients are the nonlinear function of cutting parameters[22].

In order to understand the effects of cutting parameters on the cutting force coefficients, the instantaneous force method is used to identify cutting force coefficients according to each kind of cutting condition, without thinking the effect of tool wear on the cutting force separately, therefore the cutting force coefficients under different cutting conditions are calculated based on the recognition of simulated and measured forces in the time domain. The simulated and experimental forces can be represented as the function between cutting coefficients and relevant cutting parameters: cutting time $t$, orbital angle $\theta$, rotational angle $\varphi$, and undeformed chip thickness $h$ and cutting depth $a$. In fact, it is a function of cutting force and cutting parameters, cutting time and cutting force coefficients.

The premise is that indentation force coefficients have been identified as illustrated in 3.3. Namely, supposed that corresponding experimental and simulated cutting forces are same, the cutting force coefficients can be solved from Eq.32

$\left\{\begin{array}{c}F_{x} \\ F_{y} \\ F_{z}\end{array}\right\}=\left\{\begin{array}{c}F_{x} \\ F_{y} \\ F_{z}\end{array}\right\}^{\text {Experimental }}=[A(t, \theta, \varphi, h, a)]\left\{\begin{array}{l}K_{t c} \\ K_{t e} \\ K_{r c} \\ K_{r e} \\ K_{a c} \\ K_{a e}\end{array}\right\}$

There will be three-direction cutting forces measured through experiments at time $t_{1}$, at next time $t_{2}$, there will also be three-direction cutting forces, namely, corresponding different time will have the corresponding cutting forces, thus a time period is selected as the basis for analysis. In this way, supposed that the simulated force and the 
experimental force values are equal in several discrete times, a constrained least square fitting method can be used, simultaneously in order to improve the results,

different weights and constraints could be selected for analysis to eliminate the influence of random errors. The objective is to minimize the following equation:

Where $y_{i}$ is the measured force, $f_{i}$ is function, which represents the simulated force, $m$ and $m_{p}$ are the iterative solution vector and initial estimation of cutting coefficients values, $D$ and $M$ are weighting factors. The discrete time and its corresponding measured force are substituted into the Eq.33, the constrained least square method is used to solve the instantaneous cutting coefficients, and the cutting force coefficients under different cutting conditions can be identified.

Table 3 Cutting parameters corresponding to the fitted figure

\begin{tabular}{cccc}
\hline No. & Cutting speed(m/min) & Feed rate(mm/tooth) & Axial depth of cut(mm/rev) \\
\hline Fig.11(a) & 60 & 0.04 & 0.15 \\
Fig.11(b) & 70 & 0.06 & 0.1 \\
Fig.11(c) & 80 & 0.05 & 0.2 \\
\hline
\end{tabular}

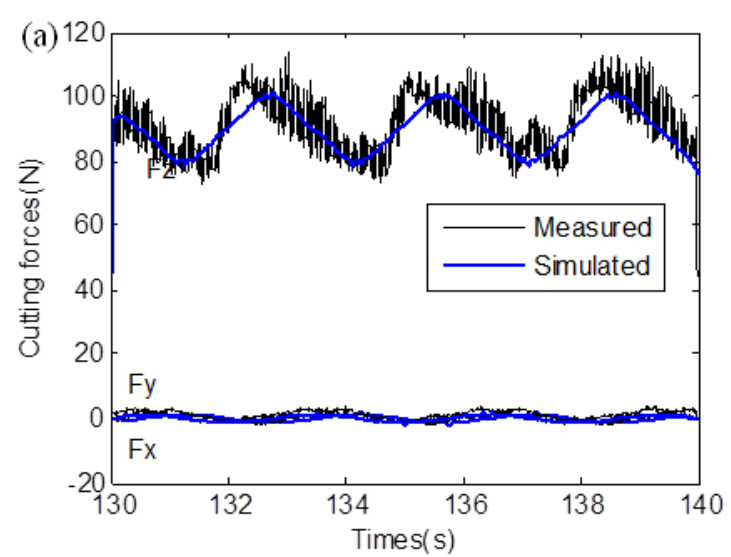

\section{Analysis and discussion}

Substituting the identified cutting force coefficients into the cutting force model, the simulated three-way forces under different cutting parameters can be obtained, and the measured forces after being filtered are drawn in the same figure with the simulated ones, the related cutting parameters corresponding to the Fig. 11 are shown in Table 3.
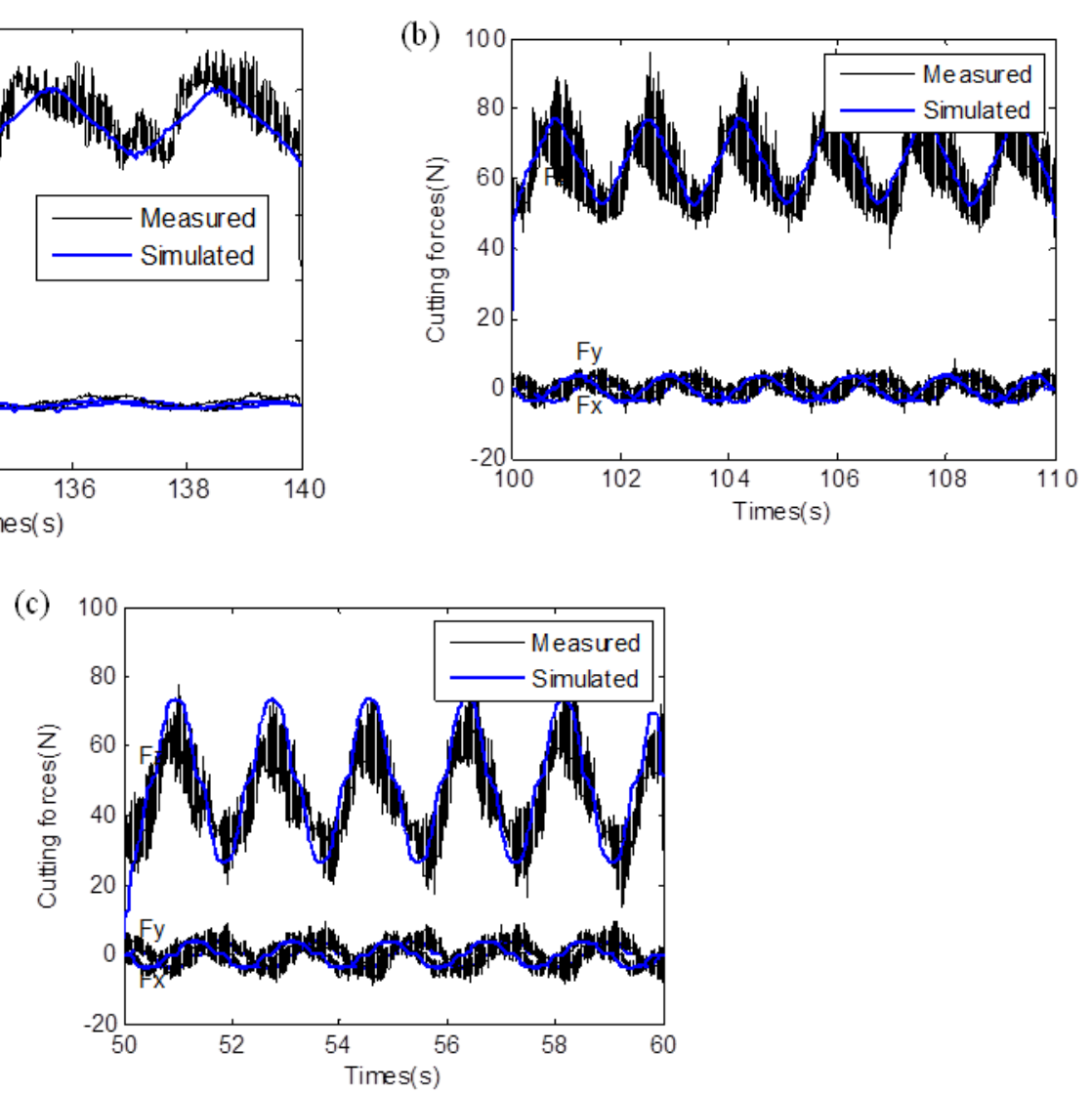
Fig.11 Comparison of simulation force and test force

The theoretical model can be used to predict the change of the cutting forces in the ball helical milling of titanium alloy when the cutting parameters change. Thus, the validation of experiments is made under state with different cutting parameters. It can be seen from Fig.11 that the simulated cutting forces are basically consistent with the measured values, although the predicted cutting forces agree well with the measured ones both in shape and magnitude, there are approximately $17 \%$ errors. The largest difference between predictions and experimental results may be due to the following reasons: first, actual measurement values have some noise interference despite filtering being taken to reduce part of the interference, which will affect the waveform of the actual measured values. Second, the analytical model assumes that the tool and workpiece are rigid and there is no tool deflection and vibration, and the effect of the tool run-out is not considered in the modeling process, which will affect not the instantaneous cutting force waveform, but the size of the cutting forces. Nevertheless, the force predictions adequately capture the general trends of the cutting forces. The presented approach is generally valid and may be extended to complex cutting state.

That is to say, the ball helical milling process cannot be simply copied general helical milling process, where side edge and bottom edge are considered respectively. The ball helical milling process must be analyzed in accordance with the kinematic principle of the cutting process. It is better to consider the circumferential and axial feed of the cutter separately.

\section{Conclusions}

- In this paper, the ball helical milling of titanium alloy was studied. The geometric shape of the tool and the contact characteristics between the tool and the workpiece were analyzed first, then the kinematic characteristics were studied. Based on the kinematic characteristics of helical milling technology, specific calculation methods were given for the motion parameters during ball helical milling process.

- According to the classic mechanical cutting force model, considering the geometry of ball-end cutters, an analytical model of the cutting force in the ball helical milling process was established. Although the axial feed velocity was relatively small, its influence on the cutting force could not be ignored. The cutting force model was modified considering the spherical cutting edge of ball end cutter.

- The indentation force coefficients were identified through linear fitted method based on cutting experiment, other cutting force coefficients were identified using instantaneous force method, cutting coefficients would change with the change of cutting parameters, these coefficients needed to be identified with each cutting parameter. The research results could be used to analyze and simulate the cutting forces under different cutting parameters.

- Cutting forces in the ball helical milling of titanium alloy under different cutting parameters were simulated, and the changing trend and the size were basically consistent, which verified the correctness of the analytical model of cutting force.

\section{References}

1.Wang HY,Qin XD (2016)A mechanistic model for cutting force in helical milling of carbon fiber-reinforced polymers. Int J Mach Tools Manuf 82 ,1485-1494

2. Wang HY, Qin XD, Ren CZ, Wang Q (2012) Prediction of cutting forces in helical milling process. Int J Adv Manuf Technol 58,849-859 
3.Liu CY,Wang G,Dargusch MS(2012)Modelling, simulation and experimental investigation of cutting forces during helical milling operations. Int $\mathrm{J}$ Adv Manuf Technol $63,839-850$

4.Ventura CEH, Hassui A(2013)Modeling of cutting forces in helical milling by analysis of tool contact angle and respective depths of cut. Int J Adv Manuf Technol 68:2311-2319

5.Zhou L, Dong HY, Ke YL, Chen GL(2018)Modeling of non-linear cutting forces for dry orbital drilling process based on undeformed chip geometry. Int J Adv Manuf Technol 94,203-216

6. Shang S, Qin XD, Li JH, Li SP, Huang T, Jin Y, Sun D (2018) Modelling of cutting forces and researching calibration method in helical milling. Int J Adv Manuf Technol 94,2949-2960

7. Rey PA, LeDref J, Senatore J, Landon Y (2016) Modelling of cutting forces in orbital drilling of titanium alloy Ti-6Al-4V. Int J Mach Tools Manuf 106,75-88

8. Li ZQ, Liu Q, Ming XZ, Wang X, Dong YF (2014) Cutting force prediction and analytical solution of regenerative chatter stability for helical milling operation. Int J Adv Manuf Technol 73(1-4),433-442

9. Li ZL, Ding Y, Zhu LM (2017) Accurate cutting force prediction of helical milling operations considering the cutter runout effect. Int $\mathrm{J}$ Adv Manuf Technol 92,4133-4144

10. Araujo AC, Guillaume FG, Poulachon G(2013)Analytical and experimental investigations on thread milling forces in titanium alloy. Int J Mach Tools Manuf 67,28-34

11. Tanaka H, Ohta K, Takizawa R, Yanagi K (2012) Experimental study on tilted planetary motion drilling for CFRP. Procedia CIRP1,443-448

12. Yucesan G, Altintas Y (1996) Prediction of ball end milling forces. Journal of engineering for industry 118,95-103

13. Altintas Y, Lee P (1998) Mechanics and dynamics of ball end milling. J Manuf Sci E-T ASME 120,684-692

14. Jia ZY, Ge J, Ma JW, Gao YY, Liu Z (2016) A new cutting force prediction method in ball-end milling based on material properties for difficult to machine materials. Int $\mathbf{J}$ Adv Manuf Technol 86,2807-2822

15. Wojciechowski S (2015) The estimation of cutting forces and specific force coefficients during finishing ball end milling of inclined surfaces. Int $\mathrm{J}$ Mach Tools Manuf $89,110-123$
16. Lee P, Altintas Y (1996) Prediction of ball-end milling forces from orthogonal cutting data. Int $\mathrm{J}$ Mach Tools Manuf 36,1059-1072

17. Engin S, Altintas Y (2001) Mechanics and dynamics of general milling cutters. Part I: helical end mills. Int $\mathbf{J}$ Mach Tools Manuf 41,2195-2212.

18. Tlusty J, MacNeil P (1975) Dynamics of cutting forces in end milling. CIRP Ann-Manuf Techn 24(1), 21-25

19. Altintas $Y$, Lee $P(1996)$ A general mechanics and dynamics model for helical end mills. CIRP Ann-Manuf Techn 45(1), 59-64

20. Dang J W, Zhang WH (2010) Cutting force modeling for flat end milling including bottom edge cutting effect. Int J Mach Tools Manuf 50,986-997

21. Gradisek J, Kalveram M, Weinert K (2004) Mechanistic identification of specific force coefficients for a general end mill. Int J Mach Tools Manuf 44, 401-414

22. Wan M, Zhang WH, Dang JW, Yang Y (2010) A novel cutting force modelling method for cylindrical end mill. Appl Math Model 34,823-836 
Figures

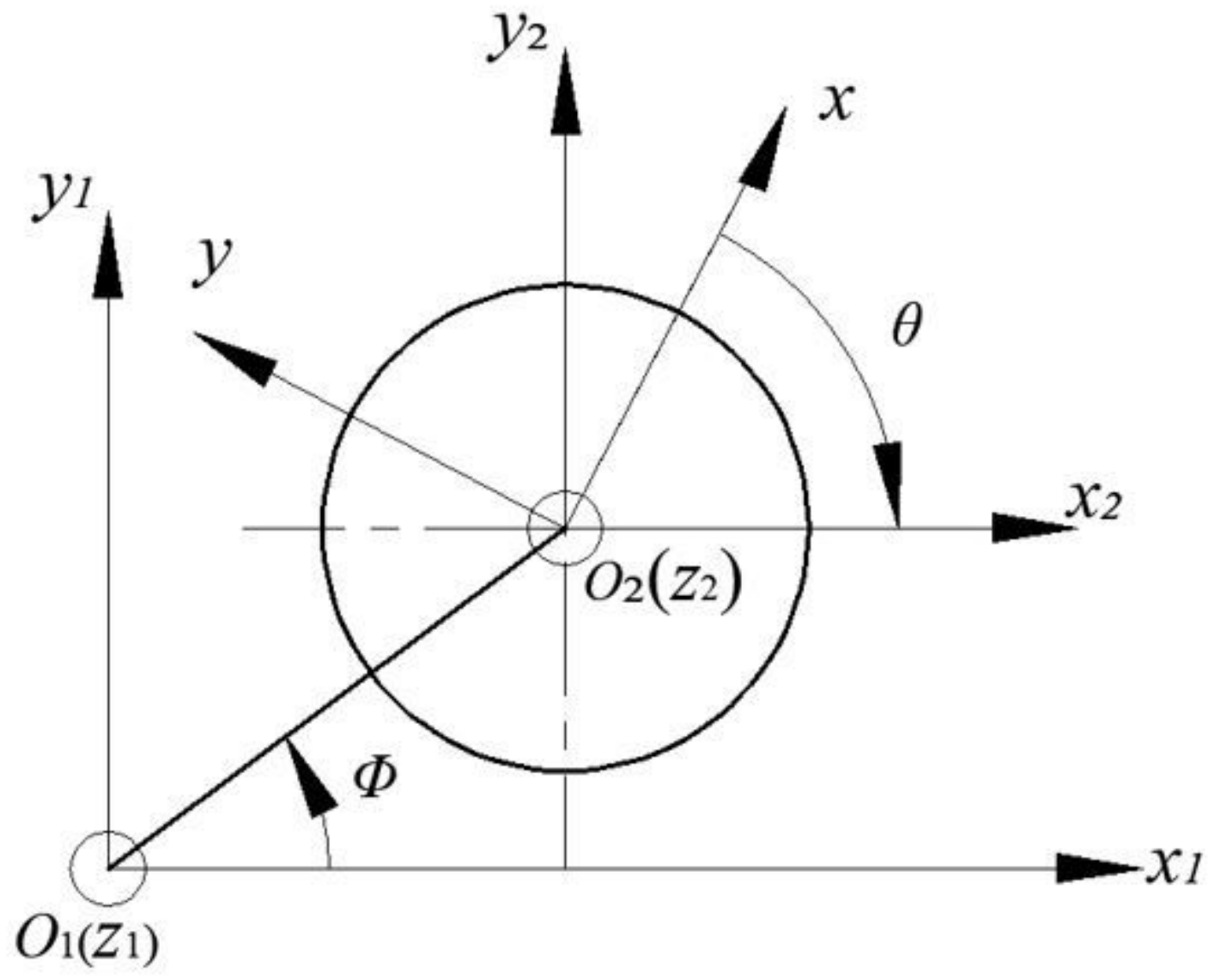

Figure 1

Coordinate system

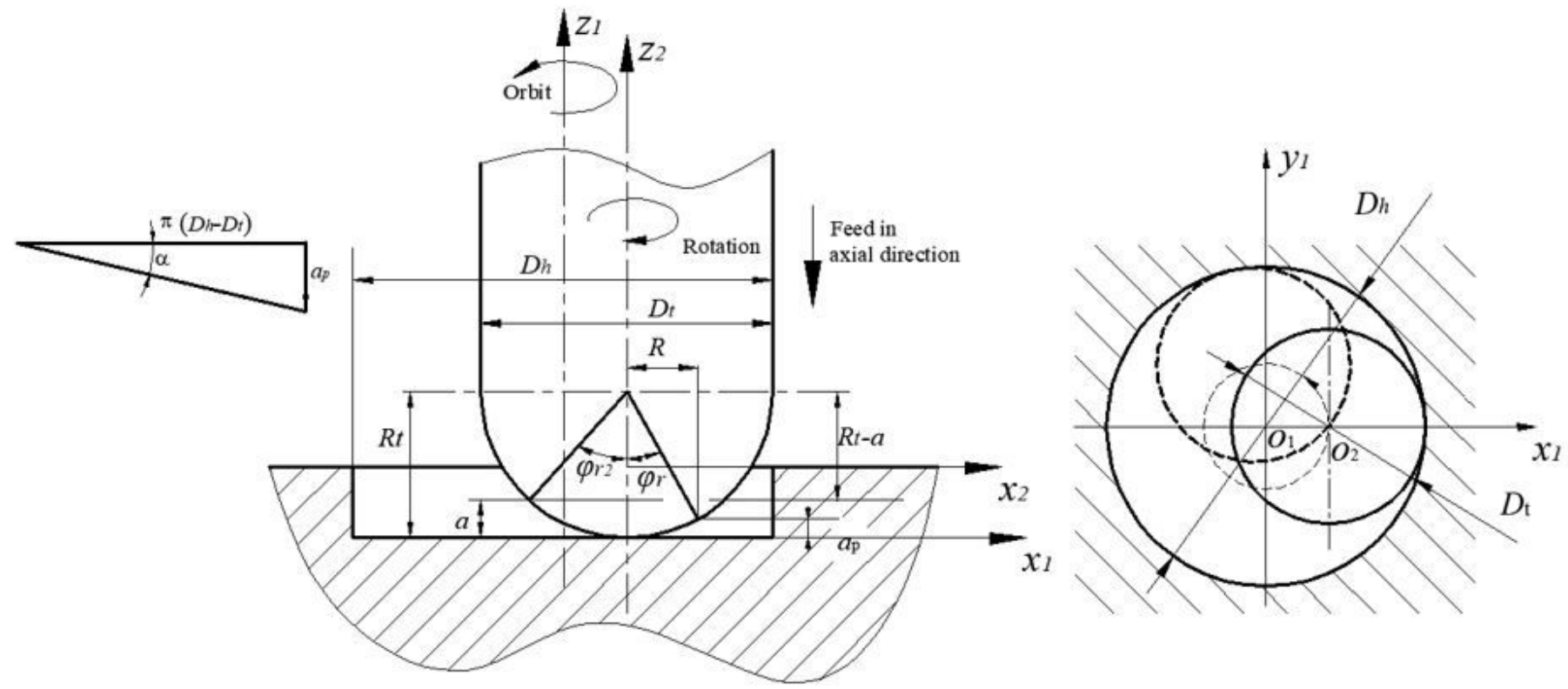


Figure 2

Cutting principle of helical milling process
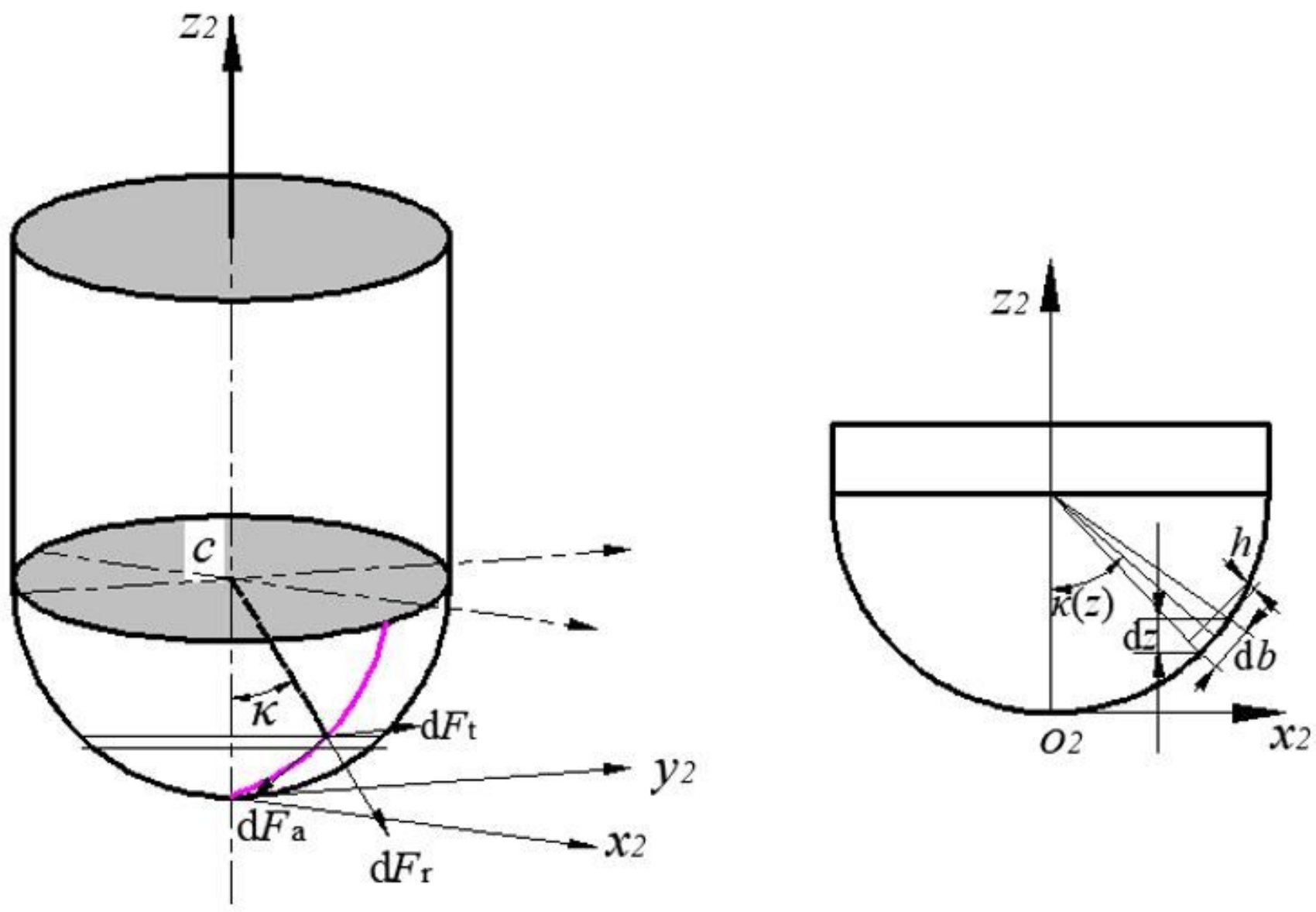

Figure 3

Geometric model of the ball end cutter 

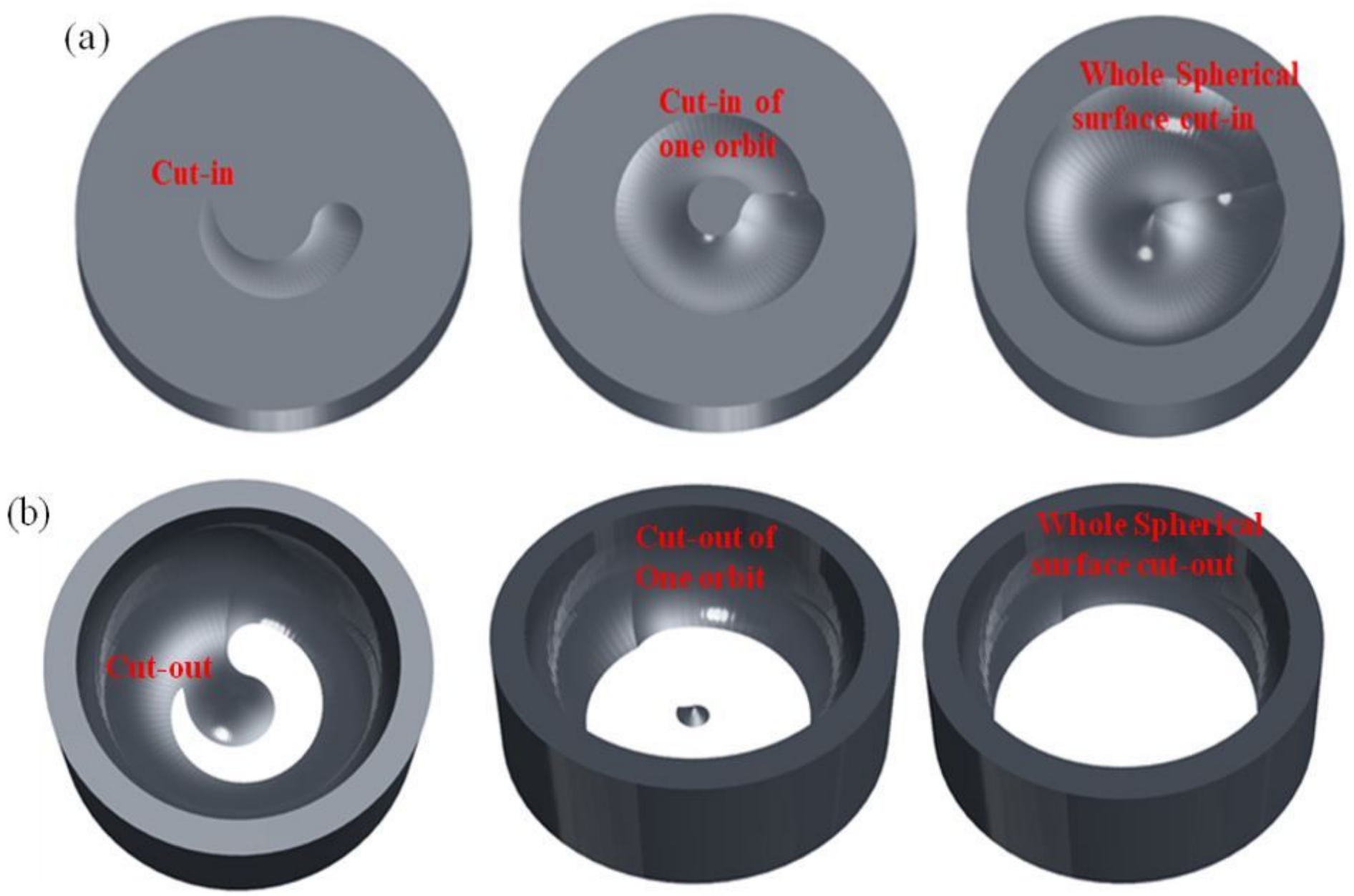

Figure 4

Cutting state in different times:(a) entry zone; (b) exit zone
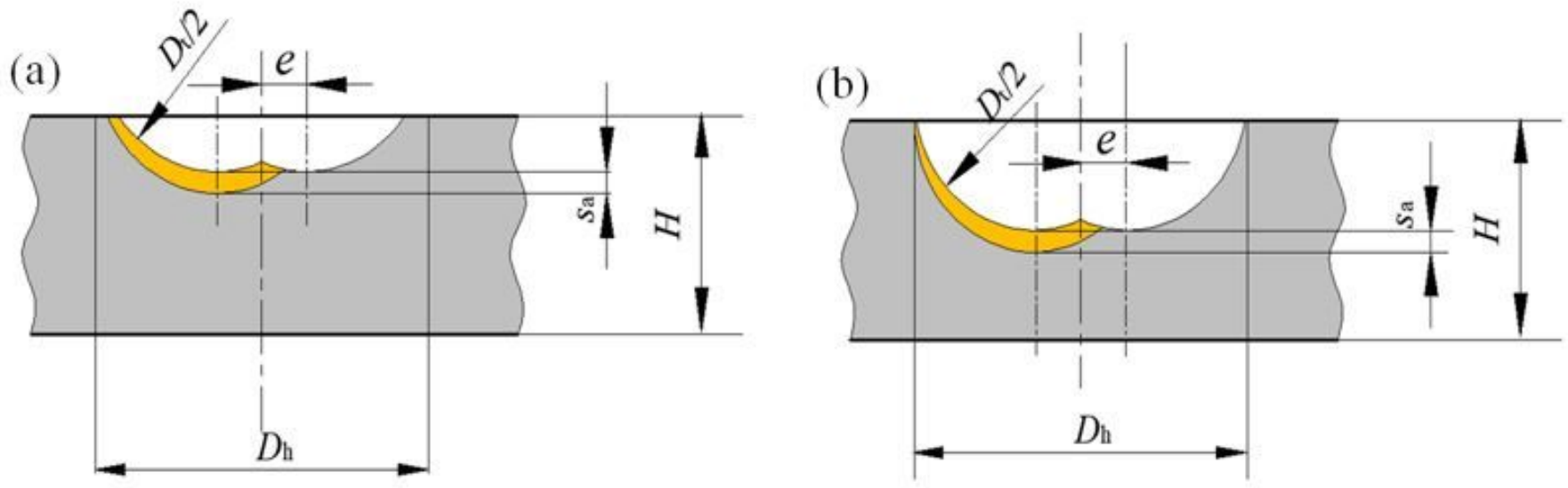

Figure 5

Schematic diagram of helical milling process: (a) local cuts,(b) fully involved 
(a)

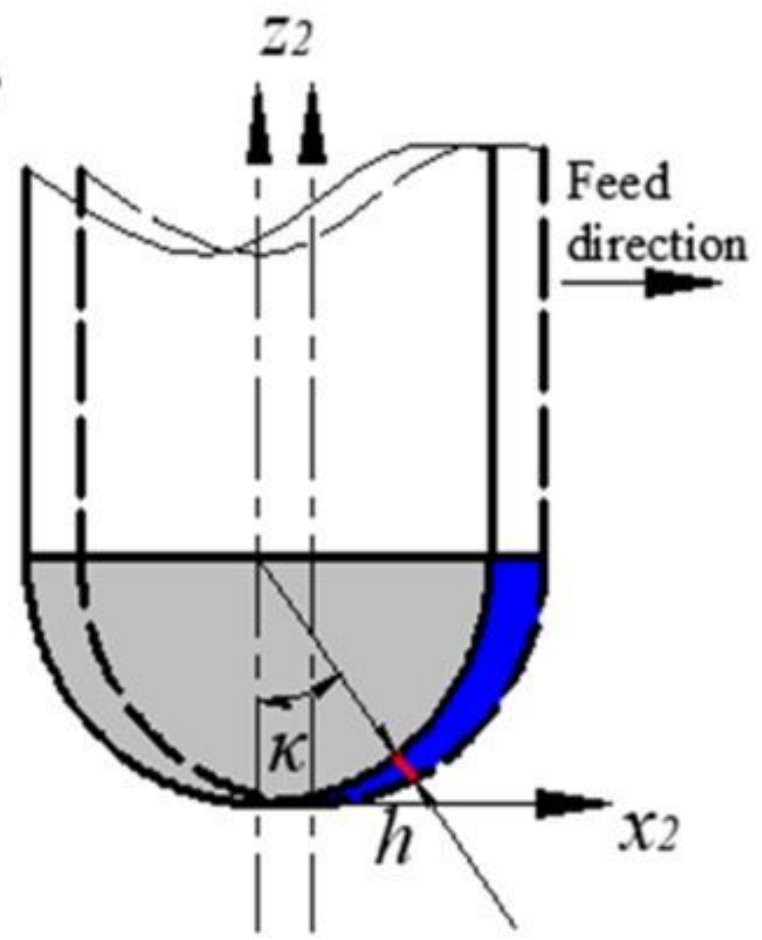

(b)

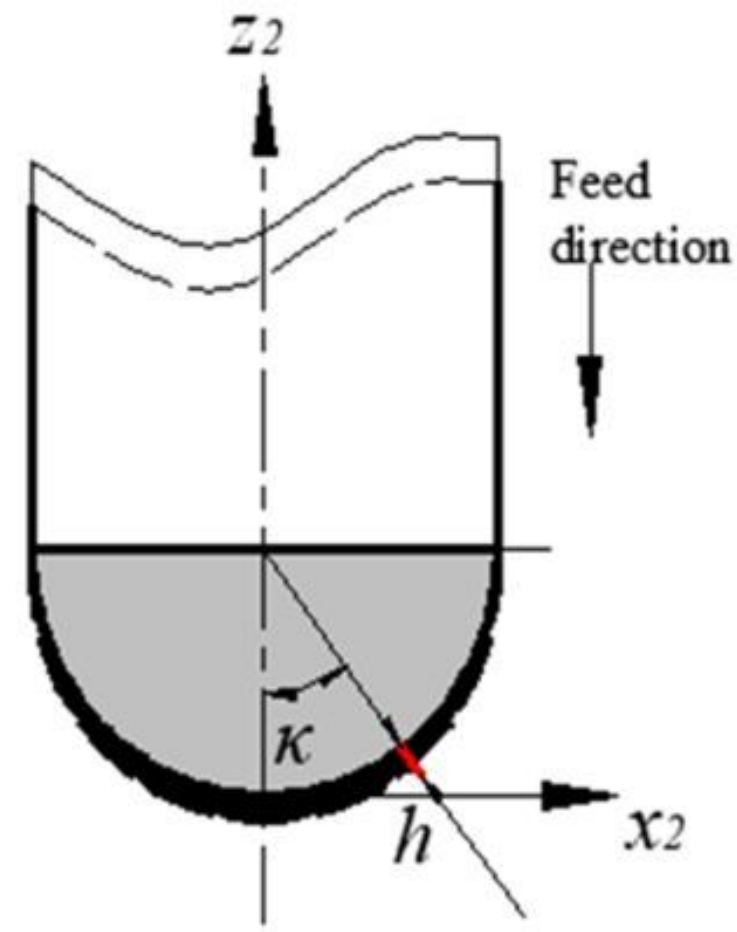

Figure 6

Undeformed chip thickness in different directions: (a) transversal feed;(b) axial feed
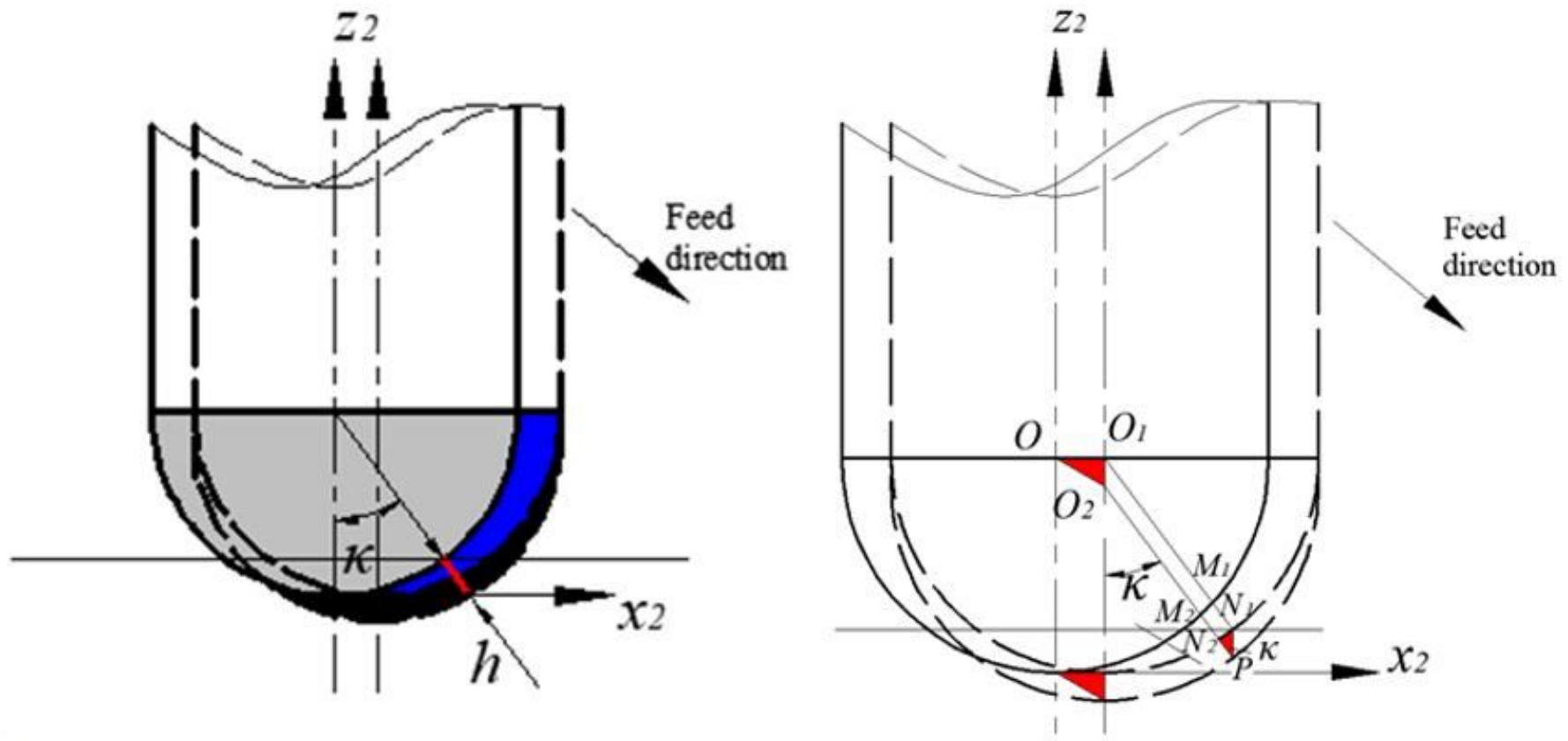

Figure 7

Determination of undeformed chip thickness 


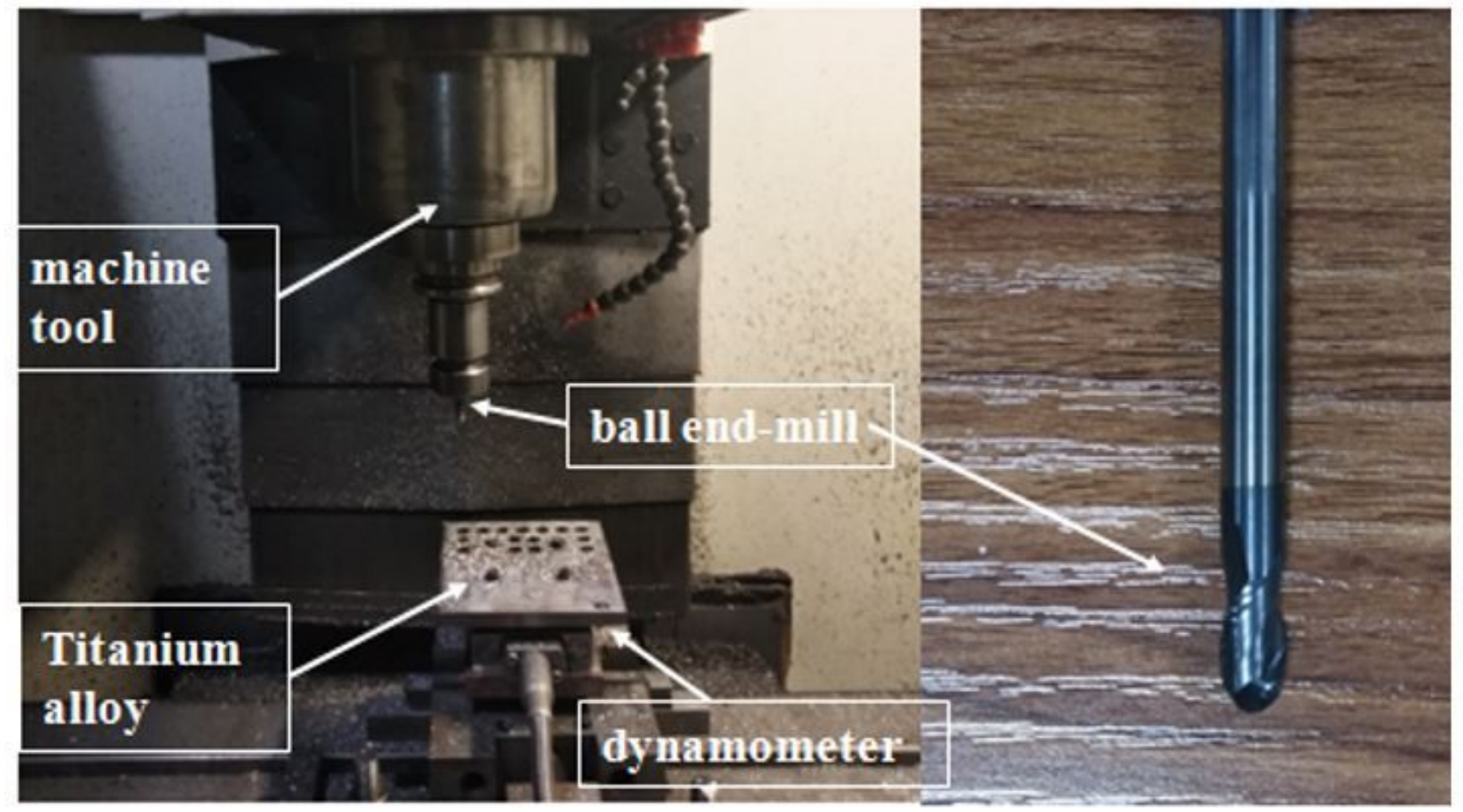

Figure 8

Cutting experiment
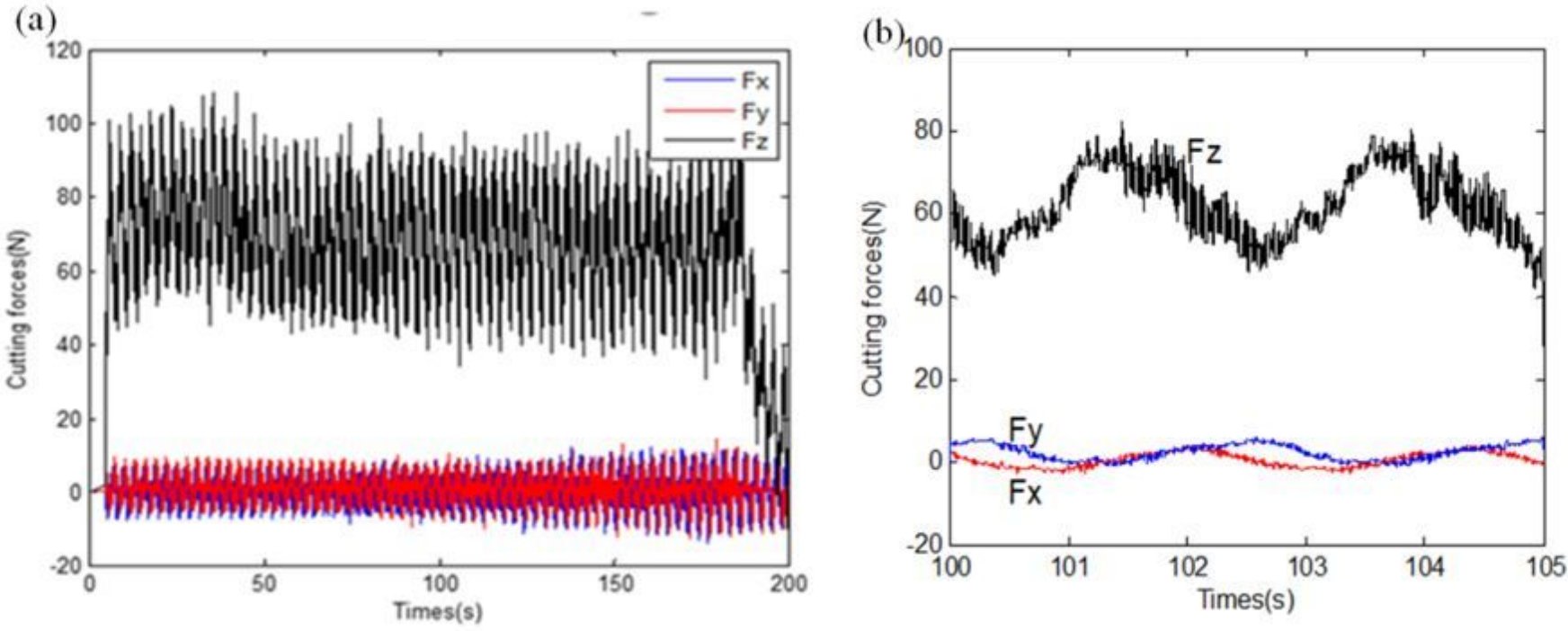

Figure 9

Cutting force data obtained from experiments: (a)original forces;(b) filtered forces 

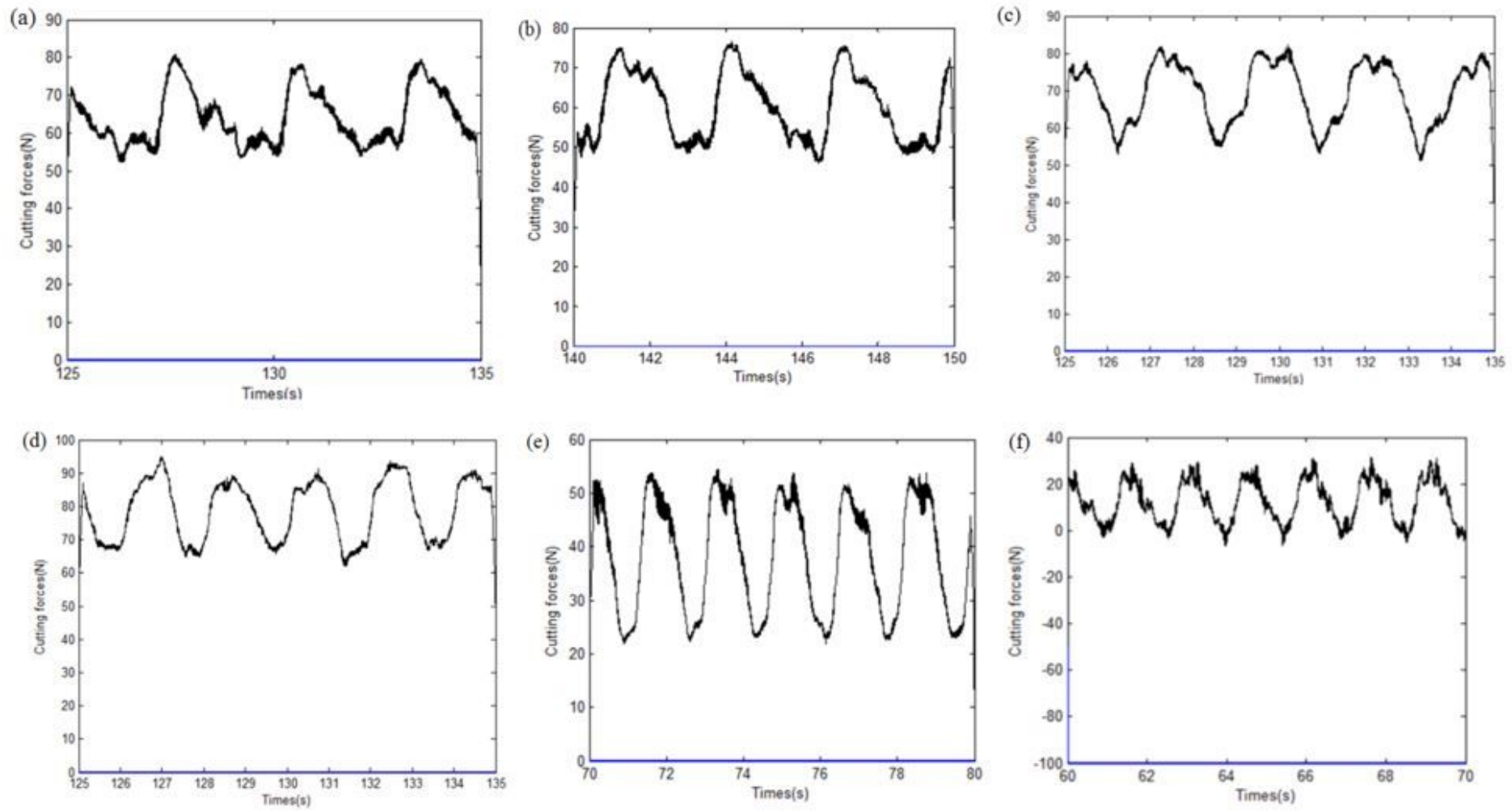

Figure 10

Axial cutting forces 

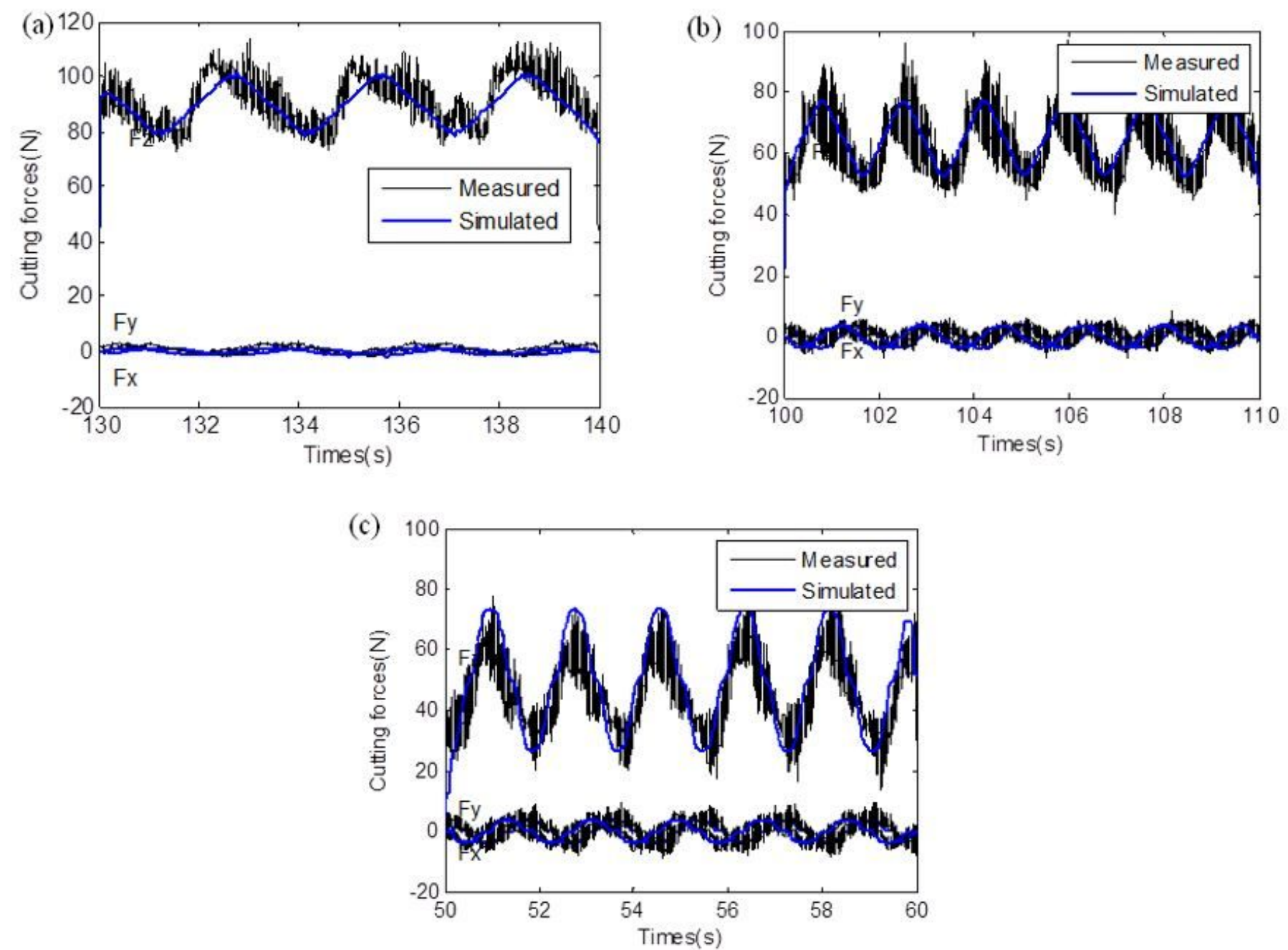

Figure 11

Comparison of simulation force and test force 